\title{
On the Structure of Resultative Participles in English
}

\section{David Embick}

The article examines the structure of resultative participles in English: participles that denote a state resulting from a prior event, such as The cake is flattened or The metal is hammered. The analysis identifies distinct stative participles that derive from the different heights at which aspectual morphemes attach in a verbalizing structure. The Aspect head involved in resultative participles is shown to attach to a vP that is also found in (a) the formation of deadjectival verbs and (b) verb phrases with resultative secondary predicates, like John hammered the metal flat. These distinct constructions are shown to have a shared structural subcomponent. The analysis proposed here is compared with Lexicalist approaches employing the verbal versus adjectival passive distinction. It is shown that a uniformly syntactic analysis of the participles is superior to the Lexicalist alternative.

Keywords: participles, adjectival passive, resultative, resultative secondary predicates, adjectives

\section{Introduction}

The division of (so-called past) participles into different varieties, often into the two categories " adjectival passive", and "verbal passive," is a familiar one. Also familiar is a commonly held approach to the differences between these participles, which relies on construction in different modules: "adjectival passives" are formed in the lexicon, while "verbal passives" are formed in the syntax.

In this article, I make a ternary distinction, among eventive passives (which are, as the name indicates, eventive) and two types of stative participles. The article begins with arguments that the binary distinction between "adjectival" and "verbal"' is too coarse. Rather than having a single type of stative participle, English has two types, which are called resultative and simply stative. The former type refers to a state that is the result of a grammatically represented event, while the latter type is a simple state, much like a simple "adjective." The analysis presented here is directed at the structure of the resultative participle. According to the "adjectival" versus "verbal" distinction, such participles would be classified as the former. The primary goal is to

For comments on the work presented here, I would like to thank Artemis Alexiadou, Rajesh Bhatt, Hagit Borer, Robin Clark, Sabine Iatridou, Tony Kroch, Rolf Noyer, and in particular Alexander Williams. Parts of this article were presented in talks at the University of Pennsylvania, the University of Texas, the University of Potsdam, the University of Maryland, the University of Southern California, the University of Delaware, the University of Stuttgart, and the Workshop on Participles at the University of Tübingen, and I would like to thank the audiences/participants for further helpful discussion. The article has also benefited greatly from the comments of anonymous $L I$ reviewers. 
identify the features and structures involved in the formation of such participles - that is, to identify their syntactic properties. The background for this treatment is provided by the theoretical position that there is only one generative component in the grammar, the syntax (see Marantz 1995, 1997, Borer 1994, 2001, for some distinct implementations); I frame this discussion in terms of Distributed Morphology (Halle and Marantz 1993). The basic outline of the approach that I develop is straightforward. A modular distinction, between lexical and syntactic derivation, cannot be the source of differences among participles, because there is no lexicon. The task that remains therefore consists of identifying the different structures and features that are responsible for the different types of participles.

After distinguishing resultative from stative participles in section 2, I address the internal structure of the resultative in section 3. Using various syntactic, morphological, and interpretive diagnostics, I show that resultative participles have a structure that is also found in (a) the formation of deadjectival verbs, such as dark-en, and (b) the formation of resultative secondary predicates, as in John hammered the metal flat. In section 4, I examine the interpretive properties of the structure I propose for resultatives and sketch its semantics. In section 5, I summarize the article and compare the syntactic approach proposed here with approaches that derive so-called adjectival passives via lexical operations. I demonstrate that the syntactic approach is superior to the lexical alternative. In this way, the analysis of participles provides a further argument in favor of nonLexicalist approaches to grammar.

\section{Statives and Resultatives}

\subsection{The Interpretations of the Participial Forms}

The different interpretations associated with participles are illustrated in (1). In making an initial distinction, I will employ the terms eventive passive and resultative for these interpretations. These terms correspond roughly to the "verbal"/"adjectival" distinction, in a manner to be articulated below.

(1) The door was opened.

\section{a. Eventive passive}

Someone opened the door.

b. Resultative

The door was in a state of having become open. (requires state resulting from an event; see Kratzer 1994)

In addition to the form and the readings in (1), there is a third form to be considered.

(2) The door was open.

This form describes a simple state, and I will therefore refer to it as a stative. For the Root $\sqrt{\text { OpEN, }}$ the resultative and the stative have distinct forms. This is not always the case, as is demonstrated below. 
Several diagnostics differentiate statives from resultatives. One, which is employed in Kratzer's (1994) discussion of participles, involves adverbial modification. Unlike pure statives, resultatives allow modification by manner (and other) adverbials. ${ }^{1}$

(3) a. The package remained carefully opened.

b. *The package remained carefully open.

(4) a. the carefully opened package

b. *the carefully open package

In other cases, an adverbial is possible with a stative, but a resultative with the same adverbial has an additional reading. Consider (5).

(5) a. the recently open door

b. the recently opened door

While (5a) is grammatical, it has only a reading in which the door was open at a recent point in the past and (probably) is no longer open. By contrast, (5b) has two readings. One is like that with open: the door was in the opened state recently, but probably is no longer. The other is that the door is in the opened state, the opening having taken place recently.

The analysis of the stative/resultative difference advanced below posits a verbalizing $\mathrm{v}$ head in the resultative, but not in the stative. The differences in adverbial modification correlate directly with the presence versus absence of this head, which is associated with verbalization and eventivity (see Travis 1994, Harley 1995, and subsequent work).

A second diagnostic distinguishing the participles from one another places the resultative or stative in an environment after a verb of creation such as build, create, make. If the complement denotes a state resulting from a prior event, there should be a contradiction. ${ }^{2}$ The following examples illustrate this with the pairs open/open-ed and long/lengthened:

(6) a. This door was built open.

b. *This door was built opened.

(7) a. This new ruler was built long.

b. *This new ruler was built lengthened.

Concentrating for expository purposes on (6), the predicates in both (6a) and (6b) are stative in the broad sense. However, as noted in the paraphrases above, there are further differences in the

\footnotetext{
${ }^{1}$ The use of diagnostics in which the participles are attributive modifiers assumes that eventive passive participles are not possible in attributive position. This assumption, the standard one in the literature, is based essentially on distributional reasoning: only "adjectives" occur prenominally. It should be noted that this assumption can be tested in nonattributive cases like (i), where the ungrammaticality of a by-phrase indicates that we are not dealing with an eventive passive.

(i) *The door remained opened by John.

However, the diagnostic cannot be used in the attributive case, for independent reasons relating to the structure of the DP in English that bar prenominal modifiers with posthead material.

${ }^{2}$ Kratzer (2000) seems to be identifying something similar, with examples such as congenitally obstructed.
} 
type of state involved that account for the contrast in acceptability. In (6a), there is no contradiction between open, which defines a simple state, and the environment in which it appears; (6b), however, is deviant because opened refers to a resultative state (i.e., one that requires a previous event), and this eventive subcomponent is incompatible with the broader context. Thus, the same Root, $\sqrt{\text { OpEN, }}$ appears in two distinct types of stative environment.

While the form open is not typically regarded as participial, there are in fact participial forms that appear in the environment in (6). For instance, closed is grammatical in this environment.

(8) This door was built closed.

There is no contradiction; this is a pure stative, and it has no event like the resultative (6b). It is also possible for this Root to have a resultative interpretation.

(9) The package remained carefully closed.

Thus, the morphophonological form clos-ed is multiply ambiguous, corresponding to both open and opened in (6).

(10)

\begin{tabular}{llll} 
Root & Stative & Resultative & Eventive passive \\
\hline$\sqrt{\text { OPEN }}$ & open- $\emptyset$ & open-ed & open-ed \\
$\sqrt{\text { CLOSE }}$ & clos-ed & clos-ed & clos-ed
\end{tabular}

Sometimes the stative and resultative have the same form, as clos-ed does; other examples are broken and bent. In many other cases, the stative form is a fossilized version of what was once a participle: for instance, drunk-en. In yet another set of cases, different "participial' allomorphs appear in the stative environment and the resultative/eventive passive environments: rotten versus rott-ed, shav-en versus shav-ed, bless-èd versus bless-ed, and so on. The table in (11) lists some of the different allomorphy patterns found in statives, resultatives, and eventive passives. ${ }^{3}$

(11)

\begin{tabular}{llll} 
Root & Stative & Resultative & Eventive passive \\
\hline$\sqrt{\text { BLESS }}$ & bless-èd & bless-ed & bless-ed \\
$\sqrt{\text { AGE }}$ & ag-èd & ag-ed & ag-ed \\
$\sqrt{\text { ROT }}$ & rott-en & rott-ed & rott-ed \\
$\sqrt{\text { SINK }}$ & sunk-en & sunk- $\emptyset$ & sunk- $\emptyset$ \\
$\sqrt{\text { SHAVE }}$ & (clean)-shav-en & shav-ed & shav-ed \\
$\sqrt{\text { OPEN }}$ & open- $\emptyset$ & open-ed & open-ed \\
$\sqrt{\text { EMPTY }}$ & empty- $\emptyset$ & empti-ed & empti-ed \\
$\sqrt{\text { DRY }}$ & dry- $\emptyset$ & dri-ed & dri-ed
\end{tabular}

${ }^{3}$ The formation of statives in this manner is not completely general; see the comments below. Some of the properties of syllabic -èd are discussed by Dubinsky and Simango (1996). 
The nature of these allomorphy patterns is discussed in detail in Embick 2003a, where I argue that the allomorphy differences seen in (11) result from structural considerations of the type I articulate below. The basic pattern is that the stative may potentially take a different participial or other allomorph than the resultative or other participial forms do. ${ }^{4}$

A third syntactic diagnostic distinguishes stative and resultative participles by their ability or inability to serve as resultative secondary predicates like flat in John hammered the metal flat (see Green 1972 and Carrier and Randall 1992 for this observation). The structure of resultative secondary predicates is examined in detail below. For present purposes, the pattern in (12)-(13) is of interest.

(12) John kicked the door closed.

(13) a. John kicked the door open/*opened.

b. Mary pounded the apple flat/*flattened.

c. Bill drank the glass empty/*emptied.

d. The heat turned the meat rotten/*rotted.

This is another environment in which statives are possible but resultatives are not.

A fourth diagnostic involves prefixation with $u n-,{ }^{5}$ which is generally quite restricted with statives, but applies more or less freely with resultatives. Recall from the discussion above that open is a stative, while open-ed is a resultative. Prefixation with un- is possible in the latter case (un-open-ed), but not the former (*un-open). The same pattern is found in other cases in which the stative and the resultative take distinct allomorphs.

(14) *un-rott-en, unrott-ed

*un-bless-èd, un-bless-ed

*un-shrunk-en, un-shrunk

There are some statives that allow un-, such as un-shav-en, or for that matter un-happy. The general pattern, however, is that un-prefixation is fully productive with resultatives, but not with statives. ${ }^{6}$

\footnotetext{
${ }^{4}$ When forms are identical, as they always are in the resultative, eventive passive, and perfect, this results from underspecification. Each of these three contexts (and the stative) involves an Asp head, into which underspecified vocabulary items insert phonological exponents -en, - ed, $-t$, and so on. See Embick 2003a for extensive discussion; among other things, basing the analysis on underspecification has the effect that the identity in form between various types of participles can be accounted for without, for instance, deriving the "adjectival passive" from the "verbal passive."

${ }^{5}$ In the earlier literature, this diagnostic surfaces in the claim that $u n$ - attaches to adjectives but not to verbs. Kratzer (1994) also makes use of the $u n$-prefixation patterns, but to a different end; see footnote 6.

${ }^{6}$ Two observations are in order here. First, the allomorphy patterns in (14) show that un-prefixation occurs with resultatives and not statives. This point is apparently at odds with Kratzer's (1994) claim that un-prefixation in German is incompatible with adverbial modification.
}

(i) a. Das Haar war hässlich gekämmt. the hair was ugly combed

'The hair was combed in an ugly way.'

b. *Das Haar was hässlich ungekämmt.

Kratzer concludes from this pattern that $u n$-prefixation is incompatible with her "phrasal adjectival passives" —in other 
A terminological excursus is in order before I undertake the structural analysis of these two participles. The first point concerns two distinct uses of the term resultative. It is clear from the examples in (13) that what I have called the resultative participle cannot appear as a resultative secondary predicate. This is potentially somewhat confusing, since the two uses of resultative appear to be at odds here; moreover, resultative secondary predication figures prominently in the second half of this article. For the discussion in this article, I will continue to use these two terms, resultative participle (sometimes simply resultative) and resultative secondary predicate, as they are both quite well established. Regarding the fact that resultative participles cannot function as resultative secondary predicates, see section 4.2. Second, the terms adjectival passive and verbal passive are employed in the discussion below because these are the traditional names assigned to certain formations. When these terms are used, it is to be understood that they are descriptive labels for categories that are found in alternative approaches to the problem. Third, by adjective I mean a category-neutral Root combined syntactically with functional structure analogous to the categorizing functional head $\mathrm{v}$ that appears with verbs.

\subsection{A Structural Approach}

According to the "verbal versus adjectival" dichotomy, both the stative and resultative types of participle are lumped under the latter heading; see section 5. They have not always been distinguished from one another in previous discussions of participles. A primary reason for this is that investigations of the different participial types have not always focused on the interpretive differences that were examined above. There are other reasons why these types of participles have not been distinguished from one another. First, they are very often identical in form. Second, they have a very similar distribution in many cases, appearing in both attributive and predicative

words, those that allow adverbial modification. As I have demonstrated in the text, un-prefixation is general with resultatives, which in many ways correspond to Kratzer's phrasal adjectival passives.

Regarding (ib), it seems that another explanation is worth exploring - in particular, that an event in the scope of negation cannot be modified by an adverbial that takes scope over the negative. Compare:

(ii) a. John quickly has become the most famous penguin-watcher in the area.

b. *John quickly hasn't become the most famous penguin-watcher in the area.

In any case, I will leave the matter open until a detailed analysis of un-prefixation can be undertaken.

Second, another noteworthy case concerns putative "voice reversals" in participles: examples such as confessed in a confessed criminal, or practiced in a practiced thief, which seem to have a perfectlike interpretation in that they are " active' (referring to one who has confessed, or one who has practiced); see Bresnan 1995. Briefly, Bresnan uses such cases to argue that the formation of adjectival passives has nothing to do with syntactic structure. It seems, however, that the cases involving such "voice reversals" are all statives in terms of the classification above. Recall that un-prefixation is fully productive with resultatives, but appears only sporadically with statives (or adjectives). It can then be shown that the "voice reversal" disappears under un-prefixation.

(iii) a. a confessed killer

b. *an unconfessed killer

c. an unconfessed crime

(iv) a. a practiced thief

b. ??an unpracticed thief

c. an unpracticed sonata

This suggests that such "voice reversals", are incompatible with the resultative structure; that is, forms such as confessed in a confessed killer are statives. In the statives, which involve attachment of Asp directly to the Root, idiosyncrasies like the one associated with the putative reversal are not unexpected; see Marantz 2001. 
position: for example, The door is open/the open door, The door is opened/the opened door. Given that the forms are often the same, the differences between stative and resultative in these environments can be quite subtle. Third, the formation of resultatives requires a particular context for many Roots (see also Kratzer 1994, 2000). For instance, (15) sounds decidedly odd out of context.

(15) The tires are kicked.

Given a scenario in which I work in a tire factory, and I have to kick all of the tires before I can go home, it becomes much better. Fourth, it seems that not all Roots form pure statives. It does

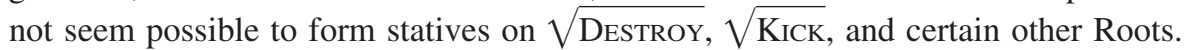

As noted above, the distinction between resultatives and statives has been made before, in the work of Kratzer (1994). For instance, parallel to the discussion of open versus opened above, Kratzer identifies differences between cool and cooled. The former is purely stative, while the latter denotes a state that is the target state of a cooling event. ${ }^{7}$

(16) a. cool: $\lambda x \lambda s[\operatorname{cool}(x)(s)]$

b. cooled: $\lambda x \lambda s \exists e\left[\operatorname{cool}(x)(s) \wedge s=f_{\text {target }}(e)\right]$

Structurally, Kratzer argues for one type of adjectival passive that involves affixation of Asp to a head, and a second type that involves affixation of Asp to a larger phrase. Although this is similar in outline to the differences between resultatives and statives presented below, many different assumptions about the nature of syntax, morphology, and the "lexicon" make the two accounts difficult to compare directly. For present purposes, then, it suffices to note that my account builds straightforwardly on the distinctions noted by Kratzer, and that the focus of this article relates quite closely to what Kratzer calls " phrasal adjectival passives.' Beyond this, the analysis presented here opens a further line of inquiry in the investigation of participial structures by relating the resultative participle to other constructions, thereby elucidating its structure.

The analysis of resultative and stative participles that I propose is structural. The essence of this type of approach, which has figured prominently in the analysis of nominalizations (see Abney 1987, Marantz 1997, Alexiadou 2001, and related work), is that the properties of "mixed" derivations are to be accounted for in terms of heads attaching to different structural positions in potentially clausal structure. The claim behind this approach is that derivation of the relevant objects is exclusively syntactic. ${ }^{8}$

Beginning with just a binary distinction between types of participles, the basic outline of a structural approach holds that there is one structure in which Asp attaches above v, the verbalizing

\footnotetext{
${ }^{7}$ Distinctions between states along these lines have been explored typologically, most notably by Nedjalkov and Jaxontov (1988).

${ }^{8}$ Single-module approaches to the different participles have been attempted in Lexicalist frameworks, such as Bresnan's (1982). Bresnan's reason for adopting this approach stems in part from an argument by Lieber (1980) to the effect that adjectival and verbal passives always show the same allomorphy. As noted in the text, the allomorphy patterns are actually more complicated than Lieber's arguments suggest. In general, analyses of the adjectival passive have proceeded on the assumption that adjectival passive formation applies to the verbal passive. Coupled with standard Lexicalist assumptions, this view has the consequence that all passive formation is lexical. The present analysis also endorses a singlemodule approach to the formation of participles, but for different reasons; see section 5 .
} 
head, and one in which it attaches directly to the $\sqrt{\text { RoOTP }}$. The $v$ is not present in structures of the latter type.

One assumption that must be highlighted is that $\mathrm{v}$ heads of the type mentioned immediately above are grammatical heads that encode eventivity and agentivity. In light of this assumption, attachment of Asp above $v$ or in a structure without $v$ as in (17) and (18), respectively, will have direct semantic consequences.

(17) Verbal passive

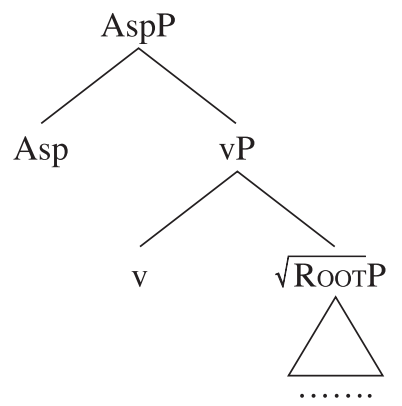

(18) Adjectival passive

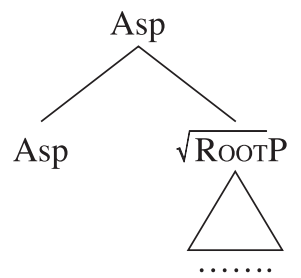

Given the binary distinction in (17) and (18), the analysis works as follows. Attachment of Asp higher than $\mathrm{v}$ as in (17) produces something eventive and agentive, corresponding to the verbal passive; attachment to the $\operatorname{Root}^{9}(\sqrt{\text { RooT }})$ as in (18) precludes the appearance of $\mathrm{v}$ and produces something that lacks the eventivity and agentivity associated with $\mathrm{v}$, corresponding to the adjectival passive. ${ }^{10}$ In either case, the Asp head is the locus of "participial" morphology; the exponents $-e d$, -en, $-t$, and $-\emptyset$ are inserted into this position to yield participles like kick-ed, writt-en, bough-t, and hit- $\emptyset$.

The structural approach thus makes a distinction between participles without $\mathrm{v}$, corresponding to adjectival passives, and participles with $\mathrm{v}$, corresponding to verbal passives. However, it has been established above that a binary classification misses the distinction between two types of participles that are stative in the broad sense, the resultative and the stative.

\footnotetext{
${ }^{9}$ By Root here I mean 'category-neutral member of the lexical (as opposed to functional) vocabulary'.

${ }^{10}$ Deriving the verbal passive via phrasal affixation and the adjectival participle via affixation to the head is argued for in Jackendoff 1977, Borer 1984, Abney 1987, and related work. An approach employing this type of distinction in a strictly syntactic theory of argument structure has been sketched more recently by Marantz in various handouts (see, e.g., Marantz 2001).
} 


\subsection{The Stative}

The structure of the stative participle provides a contrast for the discussion of section 3 , where the resultative is analyzed. The assumptions outlined above dictate that the structure for the stative should not involve $\mathrm{v}$ and its concomitant eventivity. Minimally, then, the structure for the stative is as in (19).

(19) Stative

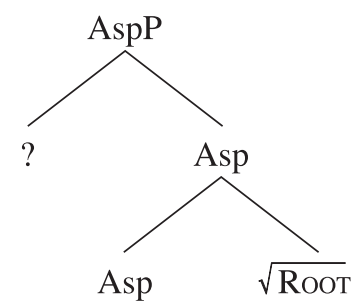

The question mark in the specifier position here indicates concerns about where the argument is actually licensed. A standard assumption is that adjectives are external predications, and the structure for the stative in (19) is essentially the same structure one would assign to, say, happy. The argument may then occupy the position where the question mark appears; but given further questions concerning, for instance, attributive versus predicative differences, I will not be able to address this issue further here.

The important point for the subsequent discussion is that the Asp head is attached to the Root. There is no $\mathrm{v}$ of any type present, hence no eventivity. This accounts for the patterns we saw above, in, for example, the diagnostic that distinguishes statives from resultatives using adverbial modification.

(20) The door remained carefully *open/opened.

The absence of $\mathrm{v}$ and its eventivity is responsible for the ungrammaticality of the adverbial modifier.

Another point of interest alluded to above is that the structure in (19) is quite similar to the one often associated with adjectives. This is, after all, what open would typically be regarded as. As the pattern with clos-ed, rott-en, bless-èd, and so on, demonstrates, participial forms with $-e d$, -en, -èd, and so on, are also associated with the structure in (19). In order to be explicit about any potential difference between Asp heads, I refer to the aspectual head that appears in statives as $A s p_{S}$ and the one that appears in resultatives as $A s p_{R}{ }^{11}$

\footnotetext{
${ }^{11}$ The question arises whether the Asp heads in the stative and resultative have the same feature content. If the interpretive differences between the stative and resultative had to be localized only in Asp, then there would of course have to be two Asp heads. However, since the stative and resultative exhibit other structural differences, such as the presence of $\mathrm{v}$ in the latter but not in the former, it is not necessary to assign all of the interpretive differences to the Asp head. The question about the number of Asp heads then amounts to the following difference: Asp $p_{R}$ defines a state out of an eventive subcomponent, while $\mathrm{Asp}_{\mathrm{S}}$ defines a simple state.
} 


\section{Structure of the Resultative}

\subsection{Preliminary Considerations}

Bearing in mind the structure of the stative, as discussed in the preceding section, a further contrast for the resultative is the eventive passive. One of the primary differences between the eventive passive and the resultative is agentivity. In resultatives, this is visible in, among other things, the fact that a by-phrase denoting the agent is not licensed. For example, (21) cannot be interpreted as a resultative; it has only the reading of an eventive passive, which, in the present tense, is habitual.

(21) The metal is hammered by John.

I assume that in the eventive passive, with the structure shown in (22), the agentive interpretation is associated with the feature $[\mathrm{AG}]$ on $\mathrm{v}^{12}$

(22) Eventive passive

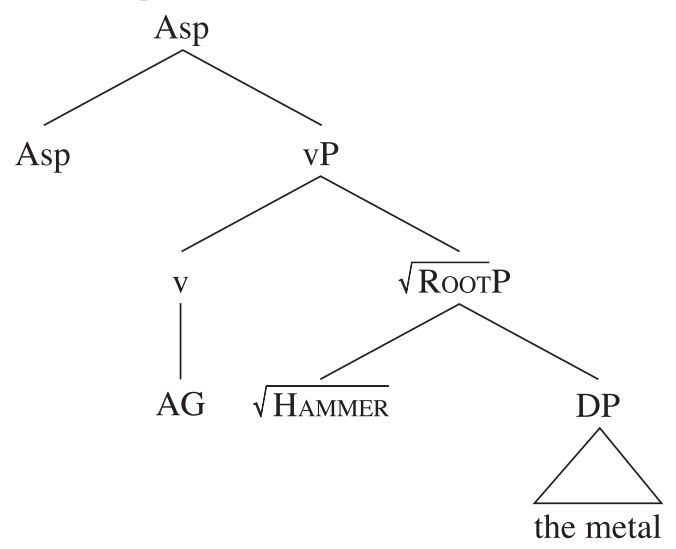

(23) Stative

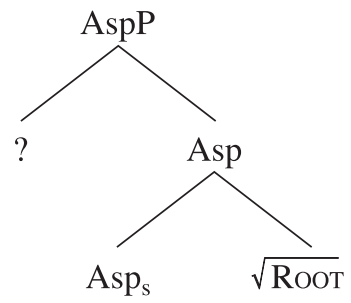

The structures for the eventive passive and the stative, the latter repeated in (23), provide boundary conditions for the structure of the resultative. Following the logic of the structural approach, the resultative involves less verbal structure than is found in (22), and more than is

${ }^{12}$ For the licensing of external arguments in this manner, see Marantz 1984 and Kratzer 1994, 1996; this structure for the eventive passive is discussed in Embick 1997, 2003b. 
found in (23). An assumption outlined in section 2 provides a further boundary condition. The resultative participle is resultative; that is to say, it denotes a state that results from a prior event. Given the assumption that eventivity of this type is encoded grammatically in the form of $v$, the complement of $\mathrm{Asp}_{\mathrm{R}}$ must include a v. Given that the resultative is not agentive, the $\mathrm{v}$ that appears in the complement of $\mathrm{Asp}_{\mathrm{R}}$ cannot be $\mathrm{v}[\mathrm{AG}]$, but must instead be another type of verbalizer.

The nature of the $\mathrm{v}$ head in question can be seen clearly in derivations involving deadjectival verbs, in which it is realized overtly as $-e n .{ }^{13}$ The verb in (24) shows overt morphology of the relevant type; and such verbs form both eventive passives and resultatives, as shown in (25).

(24) The smith flatt-en-ed the metal.

(25) a. The metal was flatt-en-ed by the smith. (eventive passive)

b. This metal is flatt-en-ed. (resultative)

c. The flatt-en-ed metal didn't impress anyone. (resultative)

Closer examination of the nature of the head that -en realizes provides an insight into the complement of $\mathrm{Asp}_{\mathrm{R}}$. The -en exponent is instantiated in both the intransitive and transitive forms. ${ }^{14}$

(26) a. The metal flatt-en-ed.

b. The smith flatt-en-ed the metal.

The fact that -en appears in the intransitive indicates that while this exponent realizes $a$ verbalizing head, it does not always realize the transitive, active $\mathrm{v}$. The transitive $\mathrm{v}$ is simply not present in (26a), which is neither transitive nor agentive. I implement the analysis of (26a-b) in terms of the structures assigned to deadjectival verbs by Hale and Keyser (1993, 1998). The relevant structures are given in (27)-(28), where Hale and Keyser's V has been changed to v in accordance with the assumption of category neutrality for Roots that I am making here.

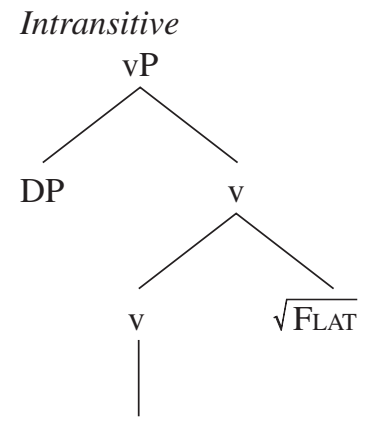

FIENT

\footnotetext{
Roots.

${ }^{13}$ When the term deadjectival is used here, it is not to be taken literally, given that I am assuming category-neutral

${ }^{14}$ It might be possible to frame the argument in terms of the affix -ize as well, as in This substance is vapor-iz-ed. The two exponents differ somewhat in that -en is found in intransitive structures more frequently than -ize; for example, This root verbalizes has the interpretation of a middle. It is also the case that -ize figures primarily in the formation of denominal verbs.
} 
(28) Transitive

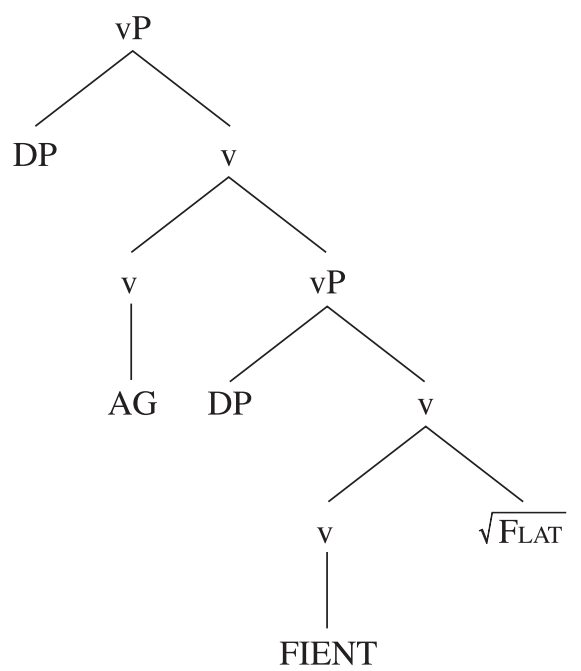

The feature [FIENT], for fientive, is a type of BECOME-operator. It denotes a becoming - or perhaps better, transition event - that moves toward a state. The difficulty in using a term like BECOME-operator, or the feature [BECOME], lies in the fact that this type of operator is often defined in terms of telic events, which is unwanted; see the discussion in Borer 2003. For this reason, I refer to the feature in question as [FIENT], with the note that it is of course related to $\mathrm{BECOME}$ and INCH (for inchoative), features familiar from the literature.

The lower head is the one associated with the verbalizing affixes; as the lower head appears in both the intransitive and the transitive, the fact that -en appears in both cases is accounted for. Given that the resultative participle (a) is not agentive and (b) contains a v head, it is the lower vP that appears as the complement of $\mathrm{Asp}_{\mathrm{R}}{ }^{15}$

From this argument, I conclude that $\mathrm{Asp}_{\mathrm{R}}$ takes a complement headed by v[FIENT], as shown in (29).

\footnotetext{
${ }^{15}$ As an anonymous reviewer points out, Pylkkänen (2002), operating with assumptions similar to those characterizing the approach here, argues against the structure in (28) for transitives. The transitive is instead formed with Root attachment of the head v[AG]. For the argument in this section, this difference is not critical. The important point is that there is a $\mathrm{v}$ head that is overtly realized as -en in resultative participles like flatt-en-ed. It is possible, however, that Root attachment in the transitive would conflict with the analysis of resultative secondary predicates proposed in section 3.2. The same reviewer also notes that evidence in favor of (28) has been presented by Cuervo (2003). As the situation is quite complex, I will not pursue it further here.
} 
(29) Resultative of flatt-en

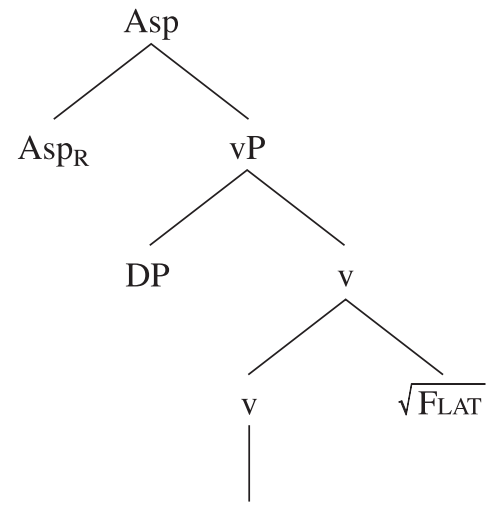

FIENT

Although the discussion immediately above is directed at deadjectival verbs, the structure in question can be extended to all resultative participles. In the earlier discussion of the resultative, the meaning of, for instance, The door is opened was paraphrased as 'The door is in a state of having become open'. Examples like The metal is hammered are interpreted similarly, as 'The metal is in a state of having become hammered'. Note that this formation behaves like a true resultative, according to the diagnostics of section $2 .^{16}$

(30) *This metal was made hammered.

The two components of this generalized treatment of resultatives are as follows. First, the complement of $\mathrm{Asp}_{\mathrm{R}}$ is defined as in (31); hence, resultative participles have the structure in (32). ${ }^{17}$

(31) Asp $_{R}$ always takes a complement headed by v[FIENT].

Second, v[FIENT] always takes a stative complement.

${ }^{16}$ An anonymous reviewer points out that (i) seems slightly better than the examples in the text.

(i) This metal was made prehammered.

I have left (i) (and (ii)) without a grammaticality marker, as the judgment seems quite subtle in these cases; many speakers find (i) ungrammatical. I think there might be an interpretation with pre- in which subparts of the object constructed are in the relevant result state. Consider (ii).

(ii) This model airplane was built prepainted.

This seems to mean that the model airplane was assembled out of individual parts that had already been painted. Whether or not there are fully grammatical examples of this type is an interesting question, but I will not pursue it further here.

${ }^{17}$ On the Asp head in resultatives stativizing a 'become' component, see also von Stechow 1996. 
(32)

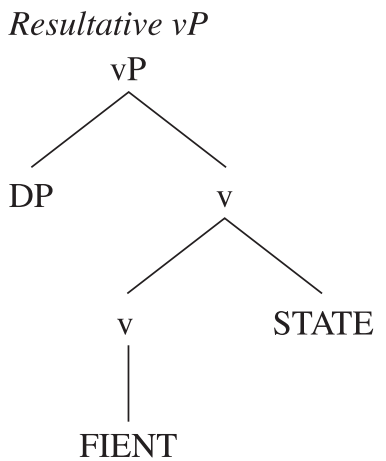

There are further conditions on what type of states may appear as the complement of v[FIENT]; I will discuss some of these as the analysis proceeds.

With these basic aspects of the analysis at hand, I now turn to a more complicated case for the analysis of resultative participles, involving sentences with resultative secondary predicates.

\subsection{Resultative Secondary Predicates}

The cases just examined above, deadjectival verbs and resultative participles, both crucially involve a state toward which the event defined by v[FIENT] moves. Another environment in which this interpretation plays a crucial role is resultative secondary predicates like the following:

(33) John hammered the metal flat.

According to the familiar paraphrase, this means something like 'John caused the metal to become/ be flat by hammering it'. In light of the interpretive connection with v[FIENT] structures just noted, and given the connection between (33) and John flattened the metal, there is strong motivation for an analysis of resultative secondary predicates that has the projection of v[FIENT] as a subcomponent. ${ }^{18}$ An additional observation that figures prominently in the discussion below is that resultative participles can be formed on structures with resultative secondary predicates.

(34) The metal is hammered flat.

For Roots like $\sqrt{\text { HAMMER, }}$, which require a bit of coercion as resultative participles, examples like (34) are extremely natural.

The relevance of examples like (34) to the analysis of participles has been noted in the literature. The naturalness of such examples is unexpected when we bring together two commonly held assumptions. According to a standard view, adjectival passives are external predications (see

\footnotetext{
${ }^{18}$ Compare, for instance, the manner in which BECOME figures in both types of formations in analyses of the semantics of these constructions such as Dowty's (1979).
} 
Borer 1984, Levin and Rappaport 1986); that is to say, they do not have internal arguments, as verbal passives would. Moreover, they are external predications that are created in the lexicon, according to the Lexicalist analysis. Thus, in The metal is hammered, the DP the metal does not originate as the object of hammer. Rather, it originates as an external argument. A second common assumption is that resultative secondary predicates, as in John hammered the metal flat, are predicated of direct objects (see Levin and Rappaport Hovav 1995 for extensive discussion). Transitives and unaccusatives pattern one way (John hammered the metal flat/The river froze solid), while unergatives require a reflexive: *John laughed hoarse but John laughed himself hoarse. This is referred to by Levin and Rappaport Hovav (1995) as the Direct Object Restriction. If both of these assumptions hold, we should never find a resultative secondary predicate with any type of nonverbal passive — such passives should have only an external argument, and therefore no resultative secondary predicate. But this is not the case (see Carrier and Randall 1992:195 n. 25, and Levin and Rappaport Hovav 1995:291 n. 8, for a statement of the problem). ${ }^{19}$

This apparent conflict does not arise if resultative secondary predicates involve v[FIENT] and the structure I have proposed above. The grammaticality of (34) is completely natural given the structure that always characterizes resultative participles, that in (32).

The analysis of these phenomena that I develop is an extension of the complex predicate analysis of resultative secondary predicates. This type of approach is implemented syntactically by Marantz (1989) (see also Larson 1988), with the structure in (35) for the lower VP of resultatives. ${ }^{20}$

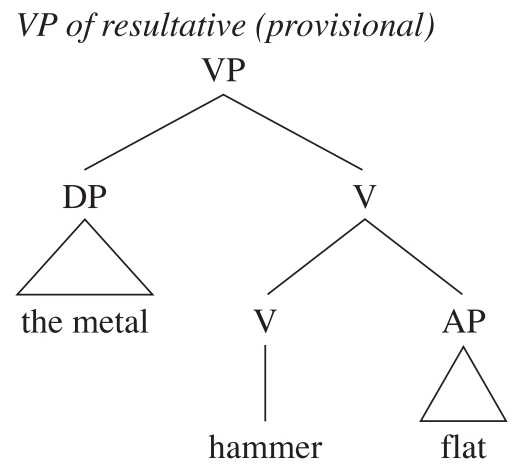

The question posed by examples like The metal is hammered flat is where hammer and flat appear in the structure (32). According to that structure, the result state always appears as the complement of v[FIENT]. This points to flat being the complement of v[FIENT], exactly as in

\footnotetext{
${ }^{19}$ More recently, Rappaport Hovav and Levin (2001) have moved away from the Direct Object Restriction in resultatives, citing work by Wechsler (1997); see Williams 2002 for a critique of this development.

${ }^{20}$ Other structures have been posited for the resultative secondary predicate (for an overview, see Winkler 1997). One that is frequently encountered involves the verb hammer taking a small clause complement (Hoekstra 1988 and subsequent work): [ $\mathrm{V}^{\prime}[\mathrm{V}$ hammer] [Small Clause[DP the metal] [AP flat]]]. See Borer 2003 and Williams 2002 for arguments against the small clause alternative.
} 
The metal is flattened. This leaves hammer to be accounted for. Consider the structure in (36), in which the Root $\sqrt{\text { HAMMER }}$ appears as part of a complex head with v[FIENT].

(36) Structure with secondary predicate

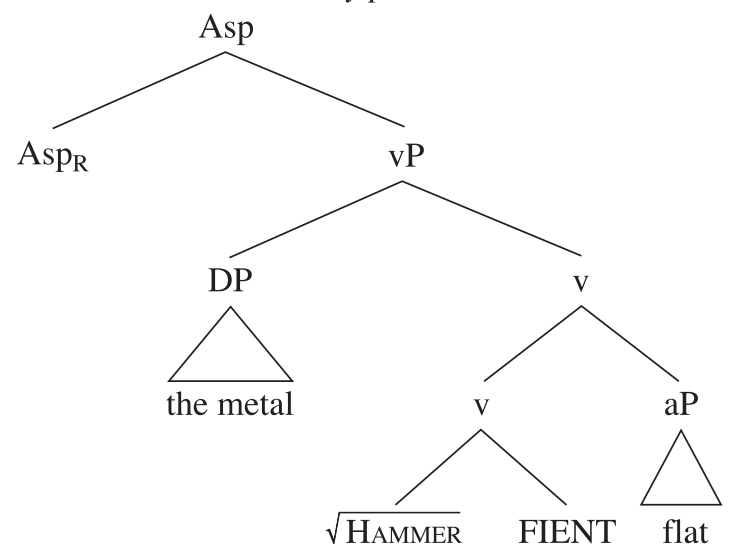

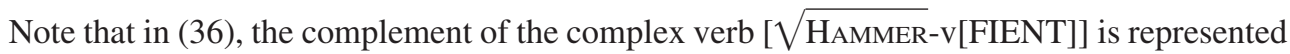
as an aP. This accounts for the availability of resultative secondary predicates like John hammered the metal flatter/completely flatlas flat as a pancake. In the discussion of flatt-en-ed above, the bare Root $\sqrt{\text { FLAT }}$ is the complement of v[FIENT]. In general, when v[FIENT] has a Root like

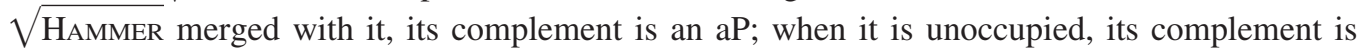
either a bare Root, which moves to v[FIENT], or perhaps an aP as well. ${ }^{21}$ I take it that v[FIENT]'s complement cannot be a bare Root when v[FIENT] has a Root merged with it because the Root in the complement position would be "uncategorized."

The statement of this pattern is similar to a proposal made by Borer (1991) for the structure of deadjectival verbs. Although I will not comment here on what lies behind the pattern, it should be noted that generalizations of this type have to figure prominently in frameworks like that of Hale and Keyser (1993), at least on the syntactic version of such an approach to argument structure that I am employing here. One important aspect of this pattern is that verbalized adjectival Roots, like $\sqrt{\text { FLAT }}$ in flatt-en, and resultative secondary predicates, like flat in John hammered the metal flat, appear in different structures. ${ }^{22}$ The former are generated as Root complements to v[FIENT], as in (37), the latter as fully phrasal aP complements, as in (38) $(A-\sqrt{R O o t}$ here abbreviates adjectival Root).

\footnotetext{
${ }^{21}$ It is possible that v[FIENT] with an aP complement is realized by light verbs like turn, as in John's face turned red, although the matter is somewhat complex.

${ }^{22}$ What it means for a Root to be "adjectival" is a matter of some interest in a theory in which Roots are assumed to be category neutral. This point is discussed in section 4.3.
} 
(37)

Verbalized root

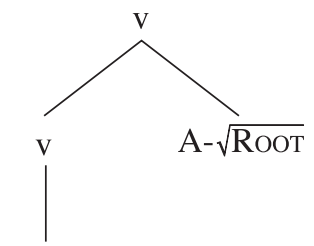

FIENT

(38)

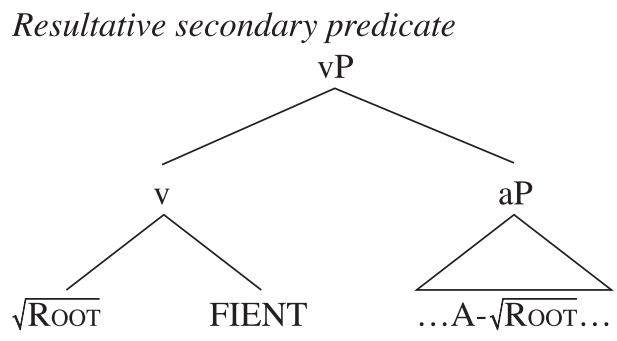

This structural difference is significant, because it correlates with a distributional difference regarding which of these two structures a Root may appear in. ${ }^{23}$ The semantic properties of adjectives that can form deadjectival verbs differ from the semantic properties of acceptable resultative secondary predicates (see Hay, Kennedy, and Levin 1999 for proposals concerning the former, Wechsler 2001 for the latter). This is an interesting point, as it makes precise some of the restrictions on (37) and (38). What is important for the present analysis is that there is a difference between the verbalization and the resultative secondary predicate contexts- that is, the difference between (37) and (38). Because these are different contexts, the Roots that are capable of appearing in each are not expected to be identical.

Structurally, (36) is a direct adaptation of the complex predicate analysis of resultative secondary predication - that is, an adaptation of (35). The component of (36) that has $\sqrt{\text { HAMMER }}$ merged with v[FIENT] is motivated by a simple morphosyntactic consideration. In sentences like John hammered the metal flat, hammer is morphosyntactically verbal; it combines with Tense, and so on. What it means to be verbal in this sense is to be combined with a v head. In (36), I assume that $\sqrt{\text { HAMMER }}$ is attached as part of a complex head with v[FIENT]; I refer to the operation that creates the complex head as Direct Merge with the head. ${ }^{24}$ This produces a single complex head, which is subsequently moved in cases like John hammered the metal flat to the higher v[AG]. It is important to note that this operation of Direct Merge has semantic consequences. The Root that is attached to v[FIENT] by this operation is interpreted as a means component; it specifies the means-the nature of the transition event-by which the result state is achieved. This point is discussed in detail in section 4. This is not the interpretation that is extended to v[FIENT]'s complements in general. Consider the structures in (39) and (40).

\footnotetext{
${ }^{23}$ The importance of this point was made clear by an anonymous reviewer.

${ }^{24}$ When v[FIENT] appears in the immediate context of $\sqrt{\text { HAMMER }}$, this head is spelled out as $-\emptyset$. It is only in the context of Roots like $\sqrt{\text { FLAT }}$ that v[FIENT] is realized as -en.
} 
(39)

Root complement

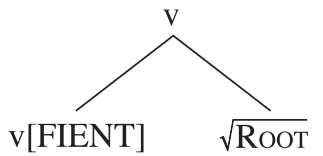

(40) Direct Merge

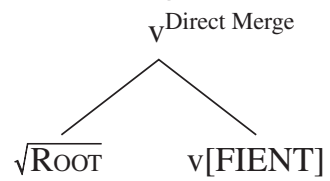

In (39), the Root is interpreted as the state toward which the transition event denoted by $\mathrm{v}$ [FIENT] moves. In (40), it is interpreted as a means component. Because sisterhood alone is not enough to determine whether a Root is directly merged or not, Direct Merge is not purely a structural notion; it is an operation that has a clear semantic component. Proposals concerning conflation operations and related operations of this type that have emerged in Hale and Keyser's approach to argument structure might be relevant for identifying the precise nature of this operation, but I will not investigate this matter further here.

Beyond these initial considerations, the structure in (36) raises the question of how $\sqrt{\text { HAMMER }}$ is interpreted and, more generally, how it is that (36) is responsible for the interpretation 'cause the metal to become flat by hammering it'. It is clearly the case that $\sqrt{\text { HAMMER }}$ is not an argument of v[FIENT] in the way that $\sqrt{\text { FLAT }}$ is in, say, The metal is flattened. Below, I give an interpretive rule for structures in which a Root is directly merged with v[FIENT] in a complex head, after first summarizing the discussion to this point.

The primary result of the analysis above is that the structure in (41) appears in resultative participles, structures with resultative secondary predicates, and deadjectival verbs. ${ }^{25}$

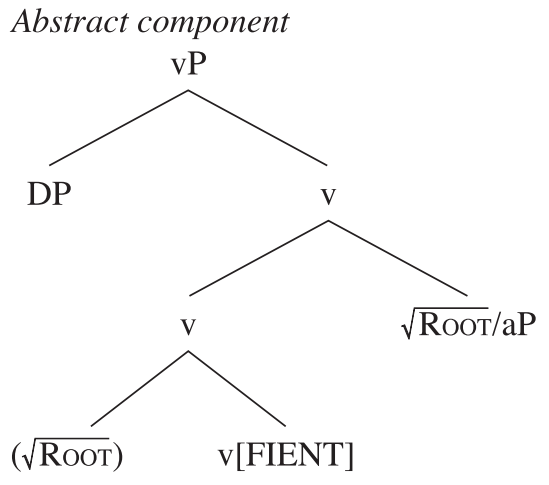

${ }^{25}$ A proposal linking the formation of deadjectival verbs with the structure of resultative secondary predicates is found in Gumiel-Molina, Nieto-Herranz, and Pérez-Jiménez 1999, although the implementation of the analysis in that paper differs from the implementation I have given above. 
Each of the cases examined involves v[FIENT] taking a stative complement. What happens to the complement of $v[$ FIENT] is determined by (a) whether or not a Root is directly merged with v[FIENT] and (b) what head takes the vP headed by v[FIENT] as its complement. A further point is that v[FIENT]'s complement is, as noted above, stative. In the case in which an aP appears as the complement of v[FIENT], no further comment is required. There is, however, something to be said about the cases in which a bare Root appears as the complement of v[FIENT]. What a bare Root by itself denotes is something of an open question. ${ }^{26}$ The analysis I have presented holds that v[FIENT] can, in effect, force its complement to be interpreted as a state. When a Root like $\sqrt{\text { DARK }}$ or $\sqrt{\text { FLAT }}$ is the complement of v[FIENT], this is reasonable, as it is safe to assume that these Roots may define states in a straightforward way. With other Roots, such as $\sqrt{\mathrm{KICK}}$, the coercive effects of v[FIENT] have consequences. The Root $\sqrt{\text { KICK }}$ does not have a characteristic state associated with it, so that examples like The tires are kicked require coercion in order to be felicitous (recall the discussion of section 2). The requirement that v[FIENT]'s complement be a state therefore provides a structural basis for the Root-specific differences that are found in the formation of resultative participles.

With these aspects of the analysis at hand, I turn now to a sketch of the interpretation of the structure for resultatives.

\section{Interpretation of v[FIENT] and the Complex Predicate}

In the preceding section, I alluded to various aspects of the interpretation of v[FIENT]. In this section, I provide a more detailed analysis of these interpretive mechanisms. I focus in particular on three separate components of the analysis of resultative participles, enumerated in (42). The first two components are dealt with below, while the third is simply sketched here.

(42) Components of the resultative participle analysis

a. The interpretation of Roots, whether these appear (i) as the complement of v[FIENT] or (ii) directly merged with v[FIENT]

b. The interpretation of $v[F I E N T]$ itself

c. The interpretation of $\mathrm{Asp}_{\mathrm{R}}$

The final component of the resultative participle in (42) is the Asp head, which takes the vP headed by v[FIENT] as its complement. This head is required because by itself the vP is eventive. Recall the cases like The metal flattened, which are fundamentally eventive, versus The metal is flattened, which is stative (= resultative). The role of $\mathrm{Asp}_{\mathrm{R}}$, then, is to create a state out of the event denoted by the vP headed by v[FIENT].

An additional role is played by the inherent properties of Roots; not every Root appears in every structural position with equal felicity. Restrictions reducing to this type of interaction are discussed in section 4.3.

\footnotetext{
${ }^{26}$ It might actually be ill formed as posed in the text, given that Roots never appear "by themselves, ' that is, without functional structure; see Marantz 1995, 1997, for discussion.
} 


\subsection{Roots and Arguments}

In examples like John hammered the metal, the important fact to note is that the Root-here, $\sqrt{\text { HAMMER }}$ - combines with a single argument: $\lambda x \operatorname{Hammer}(x)$. This is a consequence of the manner in which arguments are licensed. Assuming that external arguments are licensed by v[AG], in the manner proposed by Marantz (1984) and Kratzer (1994, 1996), a transitive vP with $\sqrt{\text { HAMMER }}$ has the structure shown in (43).

(43) $v P$

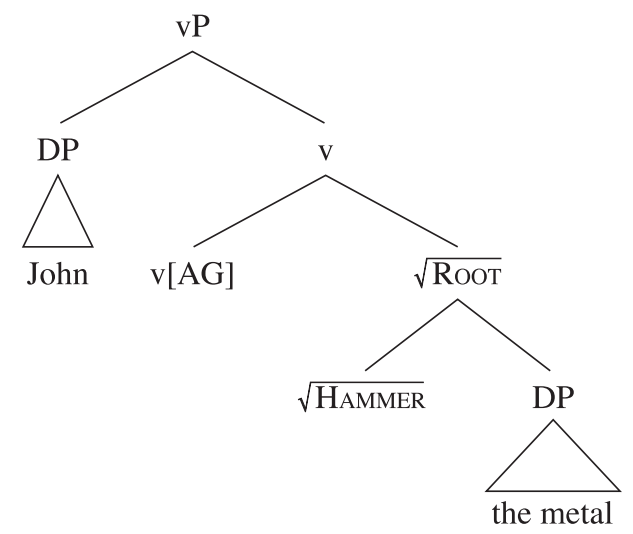

The DP that $\sqrt{\text { HAMMER }}$ combines with—-that is, the sole argument of the Root-is interpreted as its logical object. A DP in the specifier of v[FIENT]P is also interpreted as the logical object of $\sqrt{\text { HAMMER }}$ when this Root appears as the complement to v[FIENT] as in (44).

In analyzing the interpretation of v[FIENT], we may begin with the simpler case, in which this head has no Root directly merged with it. The type of structure involved here is that found with The metal flattened/is flattened and The metal is hammered. Concentrating on the latter case, the structure is as shown in (44).

(44) Resultative participle

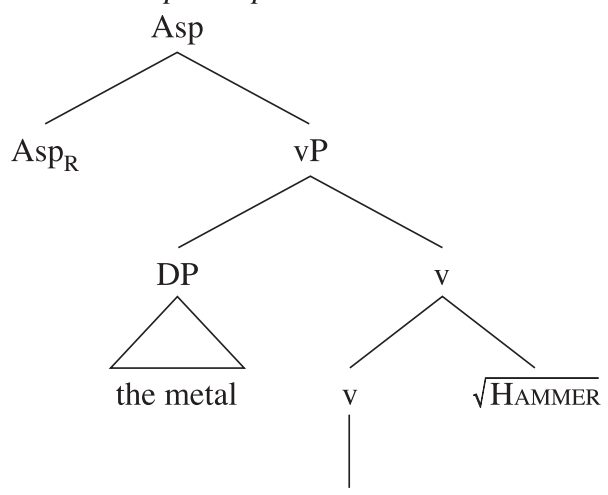

FIENT 
I take the interpretation of v[FIENT] to be $\lambda P \lambda x$ FIENT $(P(x)) .{ }^{27}$ First v[FIENT] combines with $\sqrt{\text { HAMMER }}$ to yield $\lambda x[\operatorname{FIENT}(\operatorname{Hammer}(x))]$. The DP in the specifier is then combined, to yield FIENT(Hammer(the metal)). In this analysis, the DP the metal is an argument of Hammer; it is interpreted as the logical object of Hammer because it is the first argument to combine with this Root.

If the Root that is the complement of v[FIENT] cannot take an internal argument, the analysis predicts that the resultative participle formed from this Root should be deviant. The reason for this is that the argument in the specifier of v[FIENT]P will not be interpreted. I am assuming that Roots can take at most a single argument (see Marantz 1984). The restriction to "at most" is a result of the fact that not all Roots take an argument. Unergative verbs appear in structures in which the sole argument is licensed by $\mathrm{v}[\mathrm{AG}]$, and by themselves take no argument. ${ }^{28}$ I take this to mean that, say, $\sqrt{\mathrm{LAUGH}}$ cannot combine with an argument in the way that $\sqrt{\text { HAMMER }}$ or $\sqrt{\text { FLAT }}$ can. ${ }^{29}$ As expected, the resultatives formed from such verbs are ungrammatical.

(45) a. John laughed.

b. *John is laughed.

In this case, the interpretation of the vP headed by v[FIENT] is FIENT(Laugh(John)). The Root $\sqrt{\text { LAUGH }}$ cannot be associated with an internal argument, and (45b) is accordingly impossible.

\subsection{Roots Merged with v[FIENT] and Secondary Predicates}

I now turn to the more complex case, that involving an aP resultative secondary predicate. In the analysis I have proposed, v[FIENT] in these cases has a Root directly merged with it. Above I have described the structure for the resultative, and resultative secondary predication in general, as involving a type of complex predicate. In a pretheoretical sense, this means that there is a complex verb hammer-flat involved in the examples above. However, one fact about the complex predicate that must be captured is the existence of an asymmetry between the two subparts of the predicate. Hammer flat means 'become flat by hammering', not 'become hammered by flattening'. This consideration will determine how the structure in (46) is to be interpreted.

\footnotetext{
${ }^{27}$ Here and below, I will simplify matters somewhat by not discussing event variables.

${ }^{28}$ This fact is the basis for Hale and Keyser's $(1993,1998)$ analysis, according to which unergatives are associated with "nominal" structures-for them, structures that have no complements.

${ }^{29} \mathrm{I}$ am putting aside complications with cognate objects.
} 
(46) Structure with Root merged with v[FIENT]

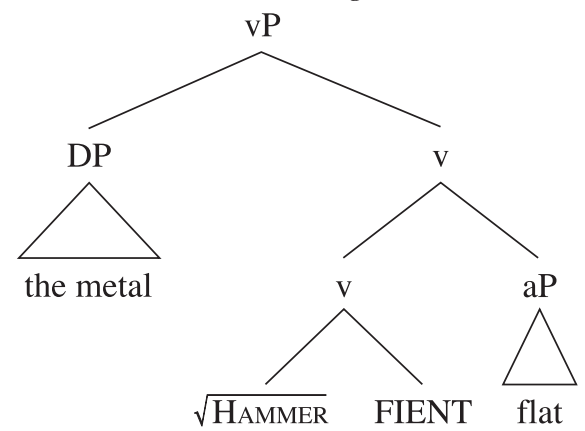

The Root directly merged with v[FIENT] specifies the means component of the complex predicate. I use the relation BY to indicate this below. The means interpretation arises from an interpretive rule that applies to structures in which a Root is directly merged with v[FIENT]. Recall that we must distinguish cases in which v[FIENT] takes a Root complement, as in (47), from cases in which v[FIENT] has a Root merged with it in a single head, as in (48). As above, the notation $v^{\text {Direct Merge }}$ indicates a v projection that is created by Direct Merge.

(47) Root complement

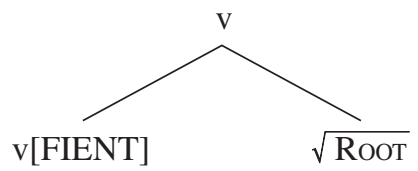

(48) Complex head

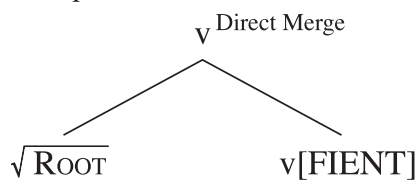

The rule responsible for the means interpretation applies to the structure (48) and determines the interpretation of the node $v^{\text {Direct Merge }}$ as in (49). In these definitions, the manner component is specified with $\mathrm{BY}$, where $\mathrm{BY}(\mathrm{X}, \mathrm{Y})$ is defined as ' $\mathrm{Y}$ comes about by $\mathrm{X}$ '. ${ }^{30}$

${ }^{30}$ Lexical rules directed at stating the relationship between a verb and a secondary predicate have been proposed in a number of works (e.g., Simpson 1983, Wunderlich 1997, Wechsler 1997), with a number of different background assumptions and frameworks.

The use of BY to relate the means and result components of the resultative relates to proposals by Dowty (1979) and Parsons (1990). 
(49) Means rule applying to the structure in (48)

a. Argument-taking Root: $\lambda P \lambda x \mathrm{BY}(\operatorname{Root}(x), \operatorname{FIENT}(P)(x)))$

b. Non-argument-taking Root: $\lambda P \lambda x \mathrm{BY}($ Root, $\operatorname{FIENT}(P(x)))$

Note that (49b) simply stipulates argument sharing between the means Root and the secondary predicate. It would be possible to account for this argument sharing through other mechanisms, so that $(49 \mathrm{a}-\mathrm{b})$ could be reduced to a single rule, but I will not undertake this reduction here.

Illustrating the derivation for (49a), which involves a Root like $\sqrt{\text { HAMMER }}$ as the means component, the next two steps involve combining with the aP headed by $\sqrt{\text { FLAT, }}$ the complement of v[FIENT], and then with the DP argument in the specifier of v[FIENT].

(50) Subsequent steps

a. $\lambda x \mathrm{BY}(\operatorname{Hammer}(x), \operatorname{FIENT}(\operatorname{Flat}(x)))$

b. BY(Hammer(the metal), FIENT(Flat(the metal)))

When $\sqrt{\text { HAMMER }}$ appears directly merged with v[FIENT] in examples like John hammered the metal flat, it retains its argument-taking properties, with the result that the DP in the specifier is interpreted as the logical object of this Root. In other cases, covered by (49b), the Roots directly merged with v[FIENT] crucially do not take the DP in the specifier of v[FIENT] as an argument; consider the so-called fake reflexive resultative in (51).

(51) John smoked himself thin.

Assuming that $\sqrt{\text { SMOKE }}$ in this case does not combine with an internal argument, the means rule applied to this Root will yield (52).

(52) $\lambda P \lambda x \mathrm{BY}($ Smoke, FIENT $(P(x)))$

Thus, in examples like John smoked himself thin we do not get the entailment 'John smoked himself'. This is a desirable outcome, although the assumption that $\sqrt{\text { HAMMER }}$ has argumenttaking properties that $\sqrt{\text { SMOKE }}$ does not in this context is by no means innocuous. ${ }^{31}$ It is important to note that argument taking or lack of argument taking by the means Root - that is, the application of (49a) or (49b) — seems to be determined by the encyclopedic properties of both the Root and the secondary predicate. Consider (53).

(53) John hammered himself thin.

This sentence has $\sqrt{\text { HAMMER }}$ as its means component, exactly as John hammered the metal flat does. However, the most natural interpretation of (53) is one in which the DP himself is not taken

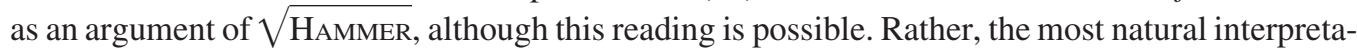
tion is parallel to that of (51), in which the DP himself is not an argument of the means Root.

${ }^{31}$ See Williams 2002 for a discussion of this question based on a crosslinguistic study. 
To determine that (49b) applies in this case, both the meaning of the Root and the meaning of the secondary predicate must be taken into account, as well as the properties of the DP in the specifier of v[FIENT]. By the same token, (51) can be interpreted with himself as the object of $\sqrt{\text { SMOKE }}$; in this case, the interpretation is that John somehow reduced his weight by exposing himself to smoke-for example, by putting himself in a smokehouse. While there are some interesting questions to explore concerning when a DP may or must be interpreted as an argument of the Root that serves as the means component, the relevant point here is that the application of (49a) versus (49b) is determined by a complex of factors, including the meanings of the means Root, the secondary predicate, and the DP that appears in the $\mathrm{vP}$, along with the interactions of these meanings. ${ }^{32}$

In conclusion, the apparent conflict between adjectival passive formation and the appearance of resultative secondary predicates simply does not arise on this analysis. Resultative participles invariably involve a head Asp taking a v[FIENT] complement. In clauses with resultative secondary predicates, the object appears in the specifier of v[FIENT] — whether it appears as a transitive, or as a resultative participle, as in (36). The structure headed by v[FIENT], shared by resultative participles, deadjectival verbal formations, and structures with resultative secondary predicates, provides a uniform basis for the syntax and interpretation of these superficially distinct constructions.

In this section, I have presented a treatment of resultative participles that relates directly to structures involving resultative secondary predicates. As noted above, since Simpson 1983, much of the syntactic discussion of resultative secondary predicates has focused on what Levin and Rappaport Hovav (1995) call the Direct Object Restriction or DOR. The DOR states that resultative secondary predicates may be predicated only of objects, not of subjects or obliques. In the present framework, the generalization that is encoded by the DOR derives from a condition on structures with v[FIENT].

\section{(54) Condition on v[FIENT]}

The complement of v[FIENT] must be predicated of a DP in the specifier of v[FIENT].

\footnotetext{
${ }^{32}$ Among the "interesting questions"' alluded to in the text, there are some apparent puzzles with respect to which combinations of means Root and resultative secondary predicate allow (49a) or (49b). As noted in the text, examples like John hammered himself thin allow either interpretation, the one in (49b) being the more natural. In this light, consider (i).

(i) The construction workers hammered me awake.

The only interpretation available for (i) seems to be one in which the workers literally woke me by hitting me with hammers. This means that in this case the DP me must be interpreted as an argument of the Root, for reasons that are not clear to me given the interpretation of (53). It seems perfectly clear what the intended (49b) interpretation of (i) is - that I was awakened by the sound of the workers' hammering - but this reading does not seem to be available. Interestingly, speakers of German I have consulted report that the equivalent of (i) has the reading in German that is missing in English.
} 
This requirement, which forces v[FIENT] to have a DP argument in an immediately local position-namely, in its specifier — subsumes the effects of the DOR. For example, the ungrammaticality of *John laughed hoarse, where the DP John is licensed as the specifier of v[AG], follows from this condition; there is no argument in the specifier of v[FIENT], and the sentence is ungrammatical. The condition has other desirable consequences as well.

A further point is that (54) applies in all environments in which v[FIENT] is found. Recall that in the simplest case, resultative participles are formed when v[FIENT] takes a Root as its complement, as illustrated in (55).

(55)

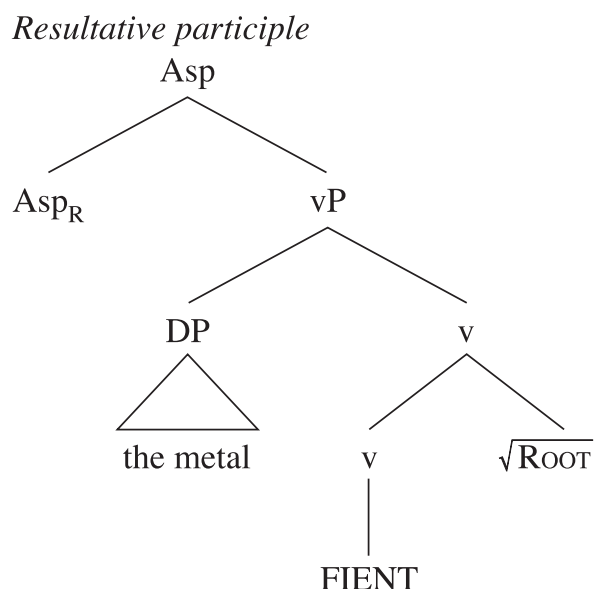

In order for (54) to be satisfied, the DP in the specifier of v[FIENT] must be taken as an argument of the Root complement of v[FIENT]. From this it follows that only certain arguments can be found in resultative participles, namely, those that are arguments of the Root itself. External arguments, and other arguments that are licensed via additional functional structure like datives, are not arguments of the Root. Hence, these arguments cannot appear in resultative participles. ${ }^{33}$

(56) a. External argument: *John is laughed.

b. Dative: *John is given a book.

Further consequences of this part of the analysis are discussed in section 5.3, where a contrast is made with Lexicalist approaches to the adjectival passive. For the moment, it is worth noting that another consequence of (54) is the contrast in (57).

(57) a. John kicked the door open.

b. *John kicked the door opened.

\footnotetext{
${ }^{33}$ The effect in (56b) is what Levin and Rappaport (1986) characterize under the heading Sole Complement Generalization; see section 5 .
} 
In (57b), opened, a resultative participle, appears as the complement to the v[FIENT] that has $\sqrt{\text { KICK }}$ merged with it. In the AspP realized as opened, there is a second v[FIENT], which is present because opened is a resultative participle. This structure is shown in (58).

(58)

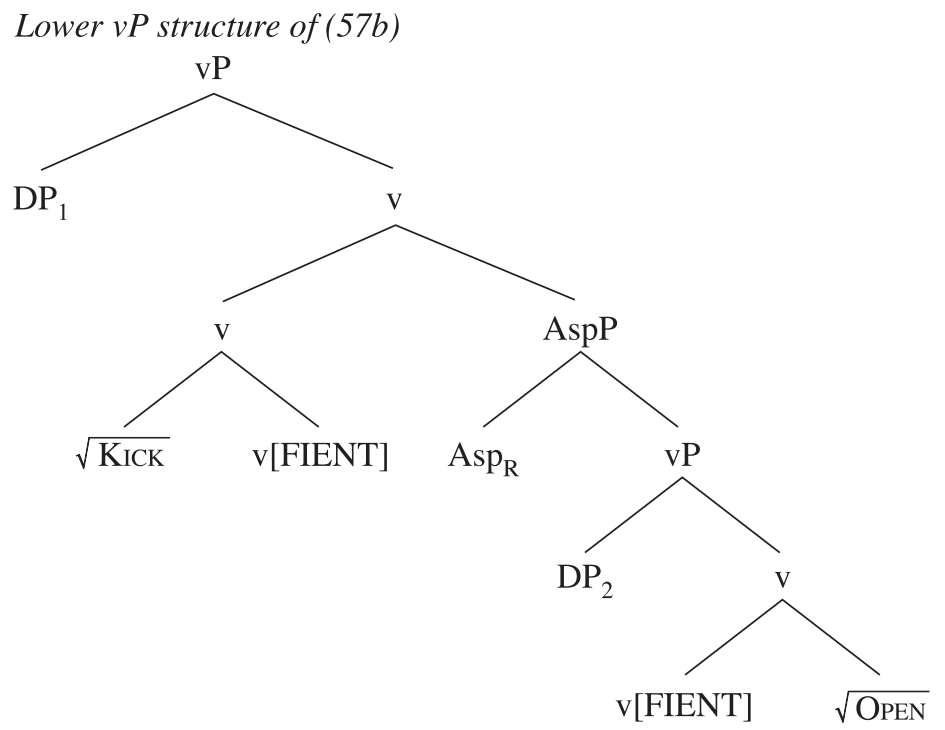

According to (54), each of these two v[FIENT] heads must have an argument in its specifier. These two positions are indicated by $D P_{1}$ and $D P_{2}$ in (58). Crucially, there is only one DP argument in (57b). Thus, (54) is violated whenever a resultative participle appears as the complement of $\mathrm{v}$ [FIENT]. Suppose that the DP the door is generated in $\mathrm{DP}_{1}$. Then the lower v[FIENT] in the AspP spelled out as opened does not have a DP argument in its specifier. If the DP is generated in $\mathrm{DP}_{2}$, the higher v[FIENT] incurs a violation of (54). Thus, examples like (57b), in which a resultative participle functions as a resultative secondary predicate, are ungrammatical. ${ }^{34}$

In addition to (54), other factors are relevant in the case of resultative secondary predications like John hammered the metal flat. The Root that is directly merged with v[FIENT] must, it seems, be of a particular type, a point to which I now turn.

\subsection{Deadjectival Verbs and Resultative Secondary Predicates}

Earlier, I noted that certain Roots require a particular context in order to be acceptable as resultatives; recall the discussion of The tires are kicked in section 2. The status of any of the examples

${ }^{34}$ At first glance, it might appear that this explanation extends to the ungrammaticality of *This door was built opened. However, resultatives can function as depictives, as (ia-b) illustrate.

(i) a. The package that we were waiting for arrived at the office [open/opened].

b. The metal shipment was sent to the station [hammered flat].

Thus, (54) is not responsible for * The door was built opened. As I noted in section 2, I think the problem is an incompatibility between the eventive semantics of the resultative in conjunction with the properties of verbs of creation. 
discussed above forces us to recognize a distinction between (a) the structure and features that underlie a particular construction and (b) the Roots that appear in (different positions in) that structure. With this distinction in focus, I now examine further implications of my analysis that arise from the interaction of structural and Root-specific factors.

One noteworthy case concerns the Roots involved in the formation of deadjectival verbs,

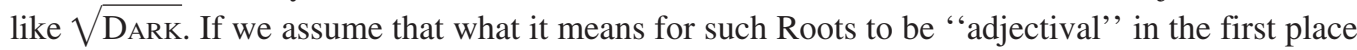
is that they can only be verbalized by virtue of appearing as v[FIENT]'s complement, as seems plausible, we derive an interesting result. Consider the contrast in (59), which shows that deadjectival verbs cannot take resultative secondary predicates.

(59) a. John colored his hair black.

b. *John darkened his hair black.

According to the analysis advanced above, this fact finds a structural explanation. With $\sqrt{\mathrm{DARK}}$, the only possible derivation is the one in which the Root originates as the secondary predicate, as in (60).

(60)

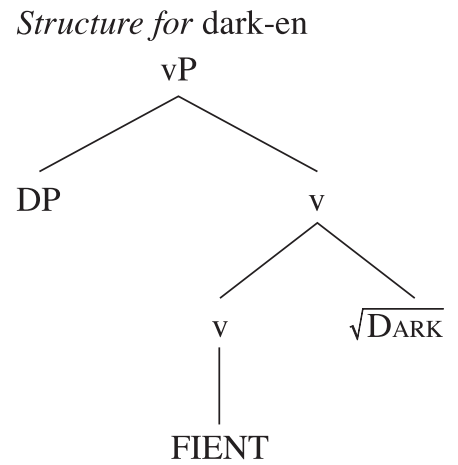

In (59b), black appears in the position in which $\sqrt{\text { DARK }}$ must originate-as the complement of $\mathrm{v}$ [FIENT]. These two objects cannot originate in the same structural position, and (59b) is therefore ungrammatical. ${ }^{35}$ It must be emphasized that this explanation can only be stated if one assumes

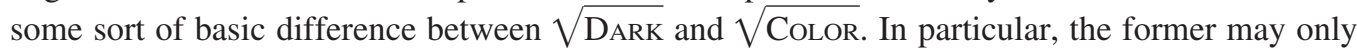
be verbalized by virtue of being v[FIENT]'s complement, while the latter is not subject to this restriction. ${ }^{36}$

An anonymous reviewer suggests that the ungrammaticality of *John darkened his hair black is due to a constraint on delimitation. In particular, Tenny (1987) and others have proposed that an eventuality may have at most one delimiter. Applied to the darken case, the idea behind this proposal is that the effect of having a resultative secondary predicate like black with a deadjectival

\footnotetext{
${ }^{35}$ Note that the explanation for (59) gives clear syntactic evidence for the type of structure adopted here for deadjectival verbs from Hale and Keyser 1993, 1998.

${ }^{36}$ Whether or not the explanation advanced for, say, $\sqrt{\mathrm{DARK}}$ is the explanation for the failure of other verbs to take secondary predicates as well is an open question; I have in mind cases like *The Romans destroyed the city flat.
} 
verb like darken results in double delimitation, hence ungrammaticality. ${ }^{37}$ This account requires the assumption that darken is inherently delimited, an assumption that could be examined in greater detail. Adopting this assumption for the moment, the account predicts that no second delimiter of any type can appear with darken. In light of this prediction, consider $(61) .^{38}$

(61) John darkened his hair to black.

This sentence, which contains a delimiter in the form of the PP to black, is perfectly acceptable. The suggestion that the ungrammaticality of (59b) derives from a general constraint barring double delimitation therefore does not seem to be on the right track. However, (61) raises a question of its own. According to the account presented above, the ungrammaticality of (59b) is structural: the aP black occupies the position in which the deadjectival Root $\sqrt{\text { DARK }}$ must originate. If this account is correct, it must be the case that the PP to black in (61) is not a "true" resultative secondary predicate; that is, the PP to black cannot be the complement of v[FIENT].

Interestingly, evidence from constituency tests seems to indicate that this conclusion is entirely correct. Consider the following examples, where the putative result phrases are long in order to control for "heaviness", effects:

(62) a. *John pounded the cutlet yesterday [flatter than a Denny's pancake].

(cf. Yesterday John pounded the cutlet [flatter than a Denny's pancake].)

b. *John pounded the yam yesterday [to a very fine and juicy pulp].

(cf. Yesterday John pounded the yam [to a very fine and juicy pulp].)

c. John darkened his hair yesterday [to a stunning shade of black].

Example (62c) with the deadjectival verb allows yesterday to appear before the putative resultPP; example (62a) with the "real" resultative secondary predicate does not. Furthermore, this contrast is not a result of category type, PP versus aP. As (62b) shows, there are resultative PPs that disallow this order as well. ${ }^{39}$

The situation is similar with do so substitution, which has been used to argue for a very close connection between means Root and resultative secondary predicate (see Levin and Rappaport Hovav 1995:49ff. for discussion; cf. also these sentences with do rather than do so $).{ }^{40}$

(63) a. *John kicked a door shut, and Mary did so open.

b. *John hammered a yam to a pulp, and Bill did so to a fine paste.

c. John darkened his hair to black, and Bill did so to chestnut brown.

\footnotetext{
${ }^{37}$ This argument parallels an argument made by Levin and Rappaport Hovav (1995:58ff.) for verbs of inherently directed motion.

${ }^{38}$ This example was pointed out by another anonymous reviewer.

${ }^{39}$ This raises the question of why the PP in (62b) apparently must be interpreted as a "true" result phrase.

${ }^{40}$ Some speakers find (63c) awkward. As an anonymous reviewer points out, this might be because of the pronominals in $(63 \mathrm{c})$. If the object is changed, the resulting example seems somewhat better.

(i) John darkened the screen to black, and Bill did so to deep gray.
} 
To summarize, the analysis I have outlined above is forced to say that the PP in (61) is not a true resultative secondary predicate; that is, it is not the complement of v[FIENT]. Constituency tests confirm this, showing that the PP to black in (61) behaves more like a type of adjunct.

Overall, then, the pattern examined in this section makes sense in terms of the connection between deadjectival verbs and resultative secondary predication advanced above. It requires further assumptions concerning Roots and their privileges of occurrence, such as " $\sqrt{\text { DARK may }}$ not be merged directly with v." Statements of this type merely encode patterns, and will do only this unless a further reduction to another domain (e.g., to the semantics of the Root) is undertaken. ${ }^{41}$ From the perspective of the present account, the importance of patterns like that in (59) is that

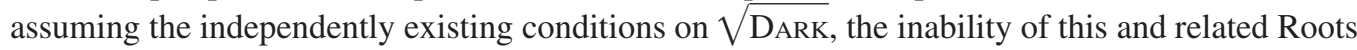
to take secondary predicates as in $(59 \mathrm{~b})$ finds a structural explanation; and the structural explanation only makes sense in terms of the common structure headed by v[FIENT] that I have proposed above.

\section{Implications and Conclusions}

The primary focus of inquiry in this article has been the structure of the resultative participle. Using the structures for the eventive passive and the stative as points of reference, I have provided an analysis in which the resultative participle always involves the structure in (64).

(64)

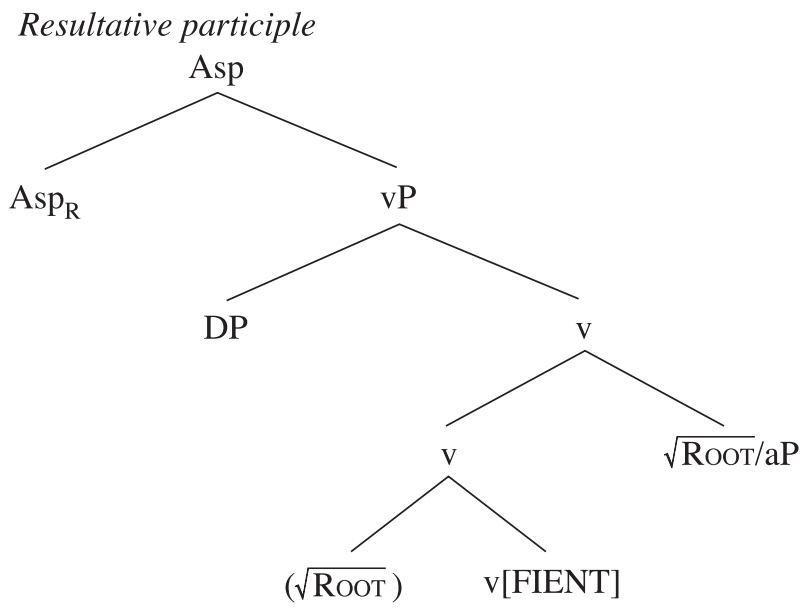

The arguments presented in favor of this structure take into account the structure of deadjectival verbs and of resultative secondary predicates, both of which were shown to involve the vP of (64) headed by v[FIENT].

${ }^{41}$ The same considerations apply to some related facts. Unlike for example $\sqrt{\mathrm{DARK}}, \sqrt{\text { HAMMER }}$ cannot function as a simple intransitive outside the resultative environment: The sky darkened versus *The metal hammered. Examples like The metal hammered flat are possible, but they have the interpretation of middles. There are connections between the analysis of resultatives presented in the text and some of the conditions on middle formation, but these are beyond the scope of the present discussion. 
The discussion in the preceding sections has advanced in strictly syntactic terms, in the sense that all of the structures and derivations examined above take place in the syntactic component of the grammar. The outcome is the structure in (64), a syntactic structure underlying resultative participles.

This syntactic approach to the analysis of participles contrasts sharply with an outlook on passivization that has been standard since the 1970s. As noted in section 1, the modes of forming the different types of participles, usually just divided into adjectival passives and verbal passives, are often assigned to different components of the grammar. According to Wasow (1977), who is most often cited in this context, verbal passives are derived syntactically, while adjectival passives are derived in the lexicon. What remains to be seen is how the syntactic approach to resultatives and statives developed here compares with the Lexicalist alternatives. Two points of comparison are considered below. In section 5.1, I address the very general question of which arguments of a verb may surface in a resultative. In section 5.2, I take up a point more specific to the facts considered in section 4 , and I show that the analysis of resultatives leads to architectural problems for Lexicalist theories.

\subsection{Arguments Found with Resultatives}

The Lexicalist approach to adjectival passive formation (APF) within the Government-Binding framework was directed at deriving an adjective from an underlying verb. According to the view put forth by Borer (1984) and adopted by Levin and Rappaport (1986), the derivation of the adjectival passive participle from the verb must involve a number of changes, including affixation of the participial morphology, category change, suppression of the verb's external argument, externalization of one of the verb's internal arguments, and so on. These changes are brought about by processes that apply in the lexicon. For the purposes of the syntax, the derived adjectival passive participle projects like an adjective.

Comparison of the syntactic approach to participles presented above with the Lexicalist alternative has to be framed against a larger set of questions about argument structure. Two competing views on how arguments are licensed are the Projectionist and non-Projectionist approaches to argument structure. The Projectionist view holds that all arguments in a clause are projected from the lexical representation of a single lexical head-namely, the verb. ${ }^{42}$ This type of approach requires that the verb be specified in the lexicon with a list of the $\theta$-roles that it assigns - a lexical argument structure. An example of a lexical argument structure for the verb sell is provided in (65), for the argument structure found in John sold a book to the visitors; the parentheses indicate that an argument is optional, and the angle brackets enclose VP-internal arguments (see Levin and Rappaport 1986).

(65) sell: agent $\langle$ theme, (goal) $\rangle$

\footnotetext{
${ }^{42}$ Or they are projected independently, but licensed by being assigned $\theta$-roles by the verb. In either case, the point is that all arguments are licensed as arguments of the verb, a single lexical head.
} 
The argument structure in (65) associates with a single lexical verb an entire list of arguments or argument roles. Such an approach to argument structure is a basic principle of Lexicalist approaches to grammar like that assumed in Levin and Rappaport's (1986) analysis of the adjectival passive. In the discussion below, I use the term Lexicalist alone to refer to approaches of this type, with the understanding that the Projectionist view of argument structure is assumed in such theories.

Unlike the Projectionist approach, the non-Projectionist approach does not require that all arguments in a clause be arguments of a single lexical head like the verb. Rather, some arguments are interpreted (i.e., "assigned a role') by virtue of the syntactic structure in which they appear. This type of approach to argument structure has already been seen above in the treatment of external arguments. As argued by Marantz (1984), external arguments are not arguments of the verb. In terms of the formalization of this idea presented by Kratzer $(1994,1996)$ and assumed above, this means that external arguments are licensed by the functional head v[AG] and are not arguments of the verb Root.

With these different views on argument licensing at hand, let us return to the formation of adjectival passives in the Lexicalist framework. A primary focus of many treatments of APF, such as Levin and Rappaport's (1986), is the nature of the arguments that may be "externalized" by APF - that is, the question of which argument of the verb can be found in an adjectival passive. In the case of a verb that assigns multiple roles like sell, it is clear that while some arguments are found in the adjectival passive, others are not (cf. (65)).

(66) The salesman sold the customers a new car.
a. Theme: a recently sold car
b. Goal: *recently sold customers

The reason for the focus on which argument may be externalized is that APF in a Lexicalist model is viewed as an operation on lexical argument structures. Thus, given an argument structure like (65), it must be determined why an adjectival passive can be formed only on the theme, and not on the goal (or for that matter the agent: *a recently sold salesman). Since all of these arguments (roles) are listed in the argument structure of the verb, some further condition must determine why some arguments may surface in the adjectival passive, while others may not.

Regarding the actual restriction, a view proposed by Wasow (1980) and Anderson (1977) held that the relevant condition made reference to $\theta$-role labels. Specifically, this proposal was that themes may be externalized by APF, while other arguments may not; this is the pattern in (66). Much of Levin and Rappaport's (1986) discussion is devoted to showing that this theme analysis is incorrect. Other verbs with two internal arguments, like serve, allow externalization of either the theme or the goal; at the same time, the verb feed allows externalization of the goal, but not the theme.

(67) The waiter served the customers food.
a. Theme: recently served food
b. Goal: recently served customers 
(68) John fed the baby carrots.

a. Theme: *recently fed carrots

b. Goal: a recently fed baby

The arguments that can be externalized in adjectival passives are not definable in terms of a single $\theta$-role like theme; rather, the relevant arguments are those that can stand alone with the verb. This is called the Sole Complement Generalization.

(69) Sole Complement Generalization

An argument that can stand as sole NP complement to a verb can be externalized by APF.

Compare (66)-(68) with (70)-(72).

(70) The salesman sold the customers a new car.

a. The salesman sold a new car.

b. *The salesman sold the customers.

(71) The waiter served the customers food.

a. The waiter served the food.

b. The waiter served the customers.

(72) John fed the baby carrots.

a. *John fed the carrots.

b. John fed the baby.

After carefully examining the types of arguments that appear with different types of double object verbs, Levin and Rappaport conclude that the argument that can be externalized by APF is not definable in terms of its $\theta$-role label. This means that some other principle must determine what arguments can be externalized. They propose that an argument that can be externalized is what they call a direct argument. The distinction between direct and indirect arguments is defined as follows:

... some of the $\theta$-roles selected by a verb may need to be assigned by other $\theta$-role assigners. ... Therefore, an NP may be an argument of a verb yet receive its $\theta$-role from a $\theta$-role assigner other than the verb. An NP assigned its role directly by the verb will be called its direct argument. An NP that is an argument of a verb but is assigned its $\theta$-role indirectly through the use of some other $\theta$-role assigner will be called an indirect argument (Marantz 1984). (Levin and Rappaport 1986:638)

Thus, the verb itself does not assign indirect argument $\theta$-roles. But the role that the argument receives is still listed in the verb's lexical argument structure. That is, in terms of representing the roles assigned to arguments, the idea is that all $\theta$-roles assigned in the clause are listed in the entry for a single lexical head, the verb. As a result, indirect arguments are treated as arguments of the verb, but they are not assigned a $\theta$-role by the verb. Rather, they are arguments of the verb in a syntactic sense: it is only in a syntactic structure in which indirect arguments are assigned a $\theta$-role by another licenser that the role listed with the verb can be associated with such an argument. 
Diagnostics for identifying the direct argument can be provided. ${ }^{43}$ However, it must be noted that even for Levin and Rappaport, the difference between direct and indirect arguments is a difference between arguments that are licensed by the Root and arguments that require additional syntactic structure to be licensed. The reason for this was stressed above: indirect arguments do not receive a $\theta$-role from the verb; instead, the role they receive is listed in the verb's lexical argument structure, but assigned by a different syntactic element. This point is very important; because the distinction between direct and indirect arguments is critical for the statement of APF, it can be demonstrated that the syntactic treatment is superior to the Lexicalist approach with lexical argument structures.

From the perspective of APF, the crucial point regarding argument roles is that the verb's argument structure includes entries for all arguments in the clause, whether they are external, direct, or indirect. Because all arguments are listed in the argument structure of the verb, APF has to be restricted in such a way as to apply to some of these arguments and not others; that is, it has to externalize direct arguments, but not indirect arguments or external arguments. Within a lexical argument structure that contains a full set of arguments, which argument is the direct argument can only be specified by stipulation - that is, by making the direct argument role look different from the other roles (e.g., Levin and Rappaport (1986) italicize the direct argument role(s) of the verb). The arguments that are singled out in this way are arguments that can be externalized by APF.

APF can be stated over lexical argument structures in this fashion. The crucial point is that because the distinction between direct and indirect arguments is ultimately syntactic, the lexical account must stipulate a condition on APF that follows automatically from the syntactic treatment. According to the Lexicalist account, indirect arguments (and for that matter external arguments) do not receive a $\theta$-role from the verb. Rather, they are arguments of the verb in the syntactic sense clarified above. But because all of these arguments are listed in the lexical argument structure of the verb, the Lexicalist approach can state the relevant conditions on APF only by notating the difference between direct and indirect arguments in the lexical argument structure; in other words, it can state the relevant conditions only diacritically. Put slightly differently, if APF is an operation on lexical argument structures, then it should in principle be able to externalize any role listed in a verb's lexical representation. The fact that APF is restricted to externalizing only direct arguments is something that can be stated in terms of the notational conventions outlined above, but it must be stressed that this restriction to direct arguments does not follow from anything. 44

${ }^{43}$ For instance, the Sole Complement Generalization seems to perform this function.

${ }^{44}$ The notational means of distinguishing types of arguments is also used for the external argument. At the time of Levin and Rappaport's article, external arguments had already been argued to be arguments of VPs, not verbs, by Marantz (1984) and Chomsky (1981). In lexical argument structures like (65) from Levin and Rappaport 1986, external arguments are often included in the representation, but diacritically distinguished from other arguments. But in principle, the fact that adjectival passives are never formed on the external argument is the result of a stipulation as well, as long as the external argument is considered to be an argument of the verb (i.e., included in lexical argument structures). 
According to the syntactic account, which eschews Projectionism and lexical argument structures, the relevant condition follows without further stipulation given the position that $\mathrm{Asp}_{\mathrm{R}}$ takes a v[FIENT] complement. This syntactic structure precludes the licensing of any other arguments that require higher functional structure. Nothing more needs to be said about what kinds of arguments can be "externalized,' because the verb has no lexical argument structure that lists all of the argument roles found in the clause; this is an essential difference between the Lexicalist and syntactic approaches. Rather, any argument that appears with a resultative participle must be interpreted as an argument of the Root. Of course, the notion " argument of the Root" corresponds to Levin and Rappaport's notion "direct argument." But the "special" status of direct arguments with respect to the formation of resultative participles does not have to be stipulated on the syntactic account. The arguments that appear in resultative participles are interpreted as arguments of the Root because the syntax of these participles excludes the structure that licenses other types of arguments; that is, there cannot be indirect arguments in the resultative, in the terminology used above. And there is no list of roles that the argument could be assigned, because there are no lexical argument structures.

In this way, the syntactic account accomplishes directly what the Lexicalist account can only accomplish by (a) adopting part of the syntactic account, in the distinction between direct and indirect argument licensing, and (b) making explicit stipulations in lexical argument structures. It is therefore superior to the Lexicalist alternative. ${ }^{45}$ Far from being a case that argues for lexical derivation, the formation of resultative participles reveals itself under close examination to be an argument for a non-Lexicalist approach to grammar; in this way, it is like the formation of nominalizations (see Marantz 1997 on Chomsky 1970).

\subsection{Architectural Problems}

A further point of comparison more specific to the analysis of this article differentiates the Lexicalist and syntactic treatments as well, once again in favor of the syntactic approach. Consider the classification of the participles that have been examined above. Both stative and resultative participles meet the criteria for being adjectival passives, by virtue of appearing as the complement of verbs like remain and as attributive modifiers.

(73) a. The door remained opened.

b. The metal remained flattened.

c. the recently hammered metal

Similarly for other diagnostics like un-prefixation: the existence of unopened and unflattened means that these participles are adjectives. According to the adjectival/verbal dichotomy, then, resultatives are created in the lexicon.

\footnotetext{
${ }^{45}$ It might seem that in an approach with lexical argument structures, it would be possible to have a nonstipulative account of APF if the indirect argument roles were not listed in the argument structure of the verb. Of course, this would be tantamount to saying that the arguments found in a clause are not represented in the argument structure of a single lexical head. That is, such a solution would abandon a basic Lexicalist principle.
} 
In terms of the distributional criteria outlined above, resultatives with resultative secondary predicates are also adjectives.

(74) a. The metal remained [hammered flat].

b. This door looks [kicked open].

This fact leads to a serious architectural problem under Lexicalist assumptions. The adjectival passives hammered flat and kicked open must be treated, given Lexicalist assumptions, as having been formed in the lexicon. The reason for this is that the process that converts a verb into an adjective has to take place in the lexicon. This is problematic, for the same reason that Lexicalist accounts of resultative secondary predication are problematic. The formation of resultative secondary predicates follows the normal principles of syntax; this is especially clear from the fact that the secondary predicate is phrasal.

(75) The metal is [hammered [ ${ }_{\mathrm{aP}}$ flatter than a pancake that has been run over by a steamroller and stomped on by elephants]].

Clearly, one would not want to derive the predicate (75) in the lexicon; it is a syntactic structure. Within standard Lexicalist assumptions, a lexical process cannot form an adjective out of hammer and the resultative secondary predicate in (75) because lexical processes cannot follow syntactic processes. Thus, the formation of resultative participles that have resultative secondary predicates must be syntactic, according to Lexicalist assumptions. If the Lexicalist view is to be maintained, this means that there must be two ways of forming resultative participles: one lexical rule for forming adjectival passive predicates like those in (73); and a second, syntactic process that creates an adjective out of hammer flat and the like.

There is, however, no motivation for maintaining a distinction between two processes forming resultative participles. The evidence supports an approach in which all resultative participles are derived in one component of the grammar: the syntax. The argument above demonstrates that the formation of some adjectives must be syntactic. Moreover, this syntactic process is one that creates participles with a resultative interpretation. Thus, it would be straightforward to derive the participles in (73) syntactically, with the consequence that all resultative participles are derived uniformly. Given the strong motivation for this syntactic treatment, the natural question to ask is whether there is any reason to maintain the idea that another type of adjective formation takes place in the lexicon. It appears that there is nothing to be gained by this move. Coupled with the arguments of the preceding section, the formation of resultative participles with resultative secondary predicates provides further evidence for a non-Lexicalist analysis of participles.

\subsection{Conclusions}

To summarize, a Lexicalist analysis of (resultative) participle formation is inferior to an exclusively syntactic treatment, where the problems adduced above do not arise. By analyzing resultative participles, deadjectival verbs, and resultative secondary predicates in terms of a uniform subcomponent - that is, a structure containing a vP headed by v[FIENT] — the analysis presented 
here accounts for a number of syntactic, morphological, and interpretive facts. It also demonstrates that the analysis of these superficially distinct constructions must view them together.

The Lexicalist approach to the formation of resultative participles (so-called adjectival passives) requires stipulations concerning the argument structure of the derived participial form; problematically for the Lexicalist approach, these stipulations on lexical representations refer ultimately to syntactic information. The syntactic account that I have presented is able to achieve the relevant restrictions on what arguments appear with resultative participles without creating this problem. As a result, the formation of such participles provides an argument for a nonLexicalist approach to grammar. Furthermore, it follows from Lexicalist assumptions that the formation of deadjectival verbs and stative participles (of either type) should occur in the lexicon, while the formation of verb phrases with resultative secondary predicates should be syntactic. Separating these formations into distinct modules makes their common properties difficult to state in a uniform way, resulting in a loss of generalization.

\section{References}

Abney, Steven. 1987. The English noun phrase in its sentential aspect. Doctoral dissertation, MIT, Cambridge, Mass.

Alexiadou, Artemis. 2001. Functional structure in nominals. Amsterdam: John Benjamins.

Anderson, Stephen. 1977. Comments on the paper by Wasow. In Formal syntax, ed. by Peter Culicover, Thomas Wasow, and Adrian Akmajian, 361-377. New York: Academic Press.

Borer, Hagit. 1984. The Projection Principle and rules of morphology. In Proceedings of NELS 14, ed. by Charles Jones and Peter Sells, 16-33. Amherst: University of Massachusetts, GLSA.

Borer, Hagit. 1991. The causative-inchoative alternation: A case study in parallel morphology. The Linguistic Review 8:119-158.

Borer, Hagit. 1994. The projection of arguments. In Functional projections, ed. by Elena Benedicto and Jeff Runner, 19-47. University of Massachusetts Occasional Papers in Linguistics 17. Amherst: University of Massachusetts, GLSA.

Borer, Hagit. 2001. Exo-skeletal vs. endo-skeletal explanations: Syntactic projection and the lexicon. Ms., University of Southern California, Los Angeles.

Borer, Hagit. 2003. The exo-skeletal trilogy. Ms., University of Southern California, Los Angeles.

Bresnan, Joan. 1982. The passive in lexical theory. In The mental representation of grammatical relations, ed. by Joan Bresnan, 3-86. Cambridge, Mass.: MIT Press.

Bresnan, Joan. 1995. Lexicality and argument structure. Paper presented at the Paris Syntax and Semantics Conference, 1995.

Carrier, Jill, and Janet Randall. 1992. The argument structure and syntactic structure of resultatives. Linguistic Inquiry 23:173-234.

Chomsky, Noam. 1970. Remarks on nominalization. In Readings in English transformational grammar, ed. by Roderick Jacobs and Peter Rosenbaum, 184-221. Waltham, Mass.: Ginn.

Chomsky, Noam. 1981. Lectures on government and binding. Dordrecht: Foris.

Cuervo, María Cristina. 2003. Datives at large. Doctoral dissertation, MIT, Cambridge, Mass.

Dowty, David. 1979. Word meaning and Montague Grammar. Dordrecht: Reidel.

Dubinsky, Stanley, and Silvester Ron Simango. 1996. Passive and stative in Chichewa: Evidence for modular distinctions in grammar. Language 72:749-781.

Embick, David. 1997. Voice and the interfaces of syntax. Doctoral dissertation, University of Pennsylvania, Philadelphia. 
Embick, David. 2003a. Locality, listedness, and morphological identity. Studia Linguistica 57.3:143-170. Embick, David. 2003b. Unaccusative syntax and verbal alternations. In The unaccusativity puzzle, ed. by Artemis Alexiadou, Elena Anagnostopoulou, and Martin Everaert, 137-158. Oxford: Oxford University Press.

Green, Georgia. 1972. Some observations on the syntax and semantics of instrumental verbs. In Papers from the Eighth Regional Meeting of the Chicago Linguistic Society, ed. by Paul M. Peranteau, Judith N. Levi, and Gloria C. Phares, 83-97. Chicago: University of Chicago, Chicago Linguistic Society.

Gumiel-Molina, Silvia, Isabel Nieto-Herranz, and Isabel Pérez-Jiménez. 1999. Some remarks on de-adjectival verbs and resultative secondary predicates. Catalan Working Papers in Linguistics 7:107-124.

Hale, Kenneth, and Samuel Jay Keyser. 1993. On argument structure and the lexical expression of syntactic relations. In The view from Building 20: Essays in linguistics in honor of Sylvain Bromberger, ed. by Kenneth Hale and Samuel Jay Keyser, 53-109. Cambridge, Mass.: MIT Press.

Hale, Kenneth, and Samuel Jay Keyser. 1998. The basic elements of argument structure. In Papers from the UPenn/MIT Roundtable on Argument Structure and Aspect, ed. by Heidi Harley, 73-118. MIT Working Papers in Linguistics 32. Cambridge, Mass.: MIT, Department of Linguistics and Philosophy, MITWPL.

Halle, Morris, and Alec Marantz. 1993. Distributed Morphology and the pieces of inflection. In The view from Building 20: Essays in linguistics in honor of Sylvain Bromberger, ed. by Kenneth Hale and Samuel Jay Keyser, 111-176. Cambridge, Mass.: MIT Press.

Harley, Heidi. 1995. Subjects, events, and licensing. Doctoral dissertation, MIT, Cambridge, Mass.

Hay, Jennifer, Christopher Kennedy, and Beth Levin. 1999. Scalar structure underlies telicity in degree achievements. In Proceedings of Semantics and Linguistic Theory 9, ed. by Tanya Matthews and Devon Strolovitch, 127-144. Ithaca, N.Y.: Cornell University, CLC Publications.

Hoekstra, Teun. 1988. Small clause results. Lingua 74:101-139.

Jackendoff, Ray. 1977. $\bar{X}$ syntax: A study of phrase structure. Cambridge, Mass.: MIT Press.

Kratzer, Angelika. 1994. The event argument and the semantics of voice. Ms., University of Massachusetts, Amherst.

Kratzer, Angelika. 1996. Severing the external argument from its verb. In Phrase structure and the lexicon, ed. by Johan Rooryck and Laurie Zaring, 109-138. Dordrecht: Kluwer.

Kratzer, Angelika. 2000. Building statives. In Proceedings of the Twenty-sixth Annual Meeting of the Berkeley Linguistics Society, ed. by Lisa J. Conathan, Jeff Good, Darya Kavitskaya, Alyssa B. Wulf, and Alan C. L. Yu, 385-399. Berkeley: University of California, Berkeley Linguistics Society.

Larson, Richard. 1988. On the double object construction. Linguistic Inquiry 19:335-391.

Levin, Beth, and Malka Rappaport. 1986. The formation of adjectival passives. Linguistic Inquiry 17: 623-661.

Levin, Beth, and Malka Rappaport Hovav. 1995. Unaccusativity: At the syntax-lexical semantics interface. Cambridge, Mass.: MIT Press.

Lieber, Rochelle. 1980. The organization of the lexicon. Doctoral dissertation, MIT, Cambridge, Mass.

Marantz, Alec. 1984. On the nature of grammatical relations. Cambridge, Mass.: MIT Press.

Marantz, Alec. 1989. Projection vs. percolation in the syntax of synthetic compounds. In Selected papers from the Annual Spring Colloquium, 95-112. Chapel Hill: University of North Carolina, UNC Linguistics Circle.

Marantz, Alec. 1995. "Cat" as a phrasal idiom: Consequences of Late Insertion in Distributed Morphology. Ms., MIT, Cambridge, Mass.

Marantz, Alec. 1997. No escape from syntax: Don't try morphological analysis in the privacy of your own lexicon. In Proceedings of the 21st Penn Linguistics Colloquium, ed. by Alexis Dimitriadis, Laura Siegel, Clarissa Surek-Clark, and Alexander Williams, 201-225. Philadelphia: University of Pennsylvania, UPenn Working Papers in Linguistics. 
Marantz, Alec. 2001. Words and things. Handout, MIT, Cambridge, Mass.

Nedjalkov, Vladimir, and Sergei Jaxontov. 1988. The typology of resultative constructions. In Typology of resultative constructions, ed. by Vladimir Nedjalkov and Bernard Comrie, 3-64. Amsterdam: John Benjamins.

Parsons, Terence. 1990. Events in the semantics of English. Cambridge, Mass.: MIT Press.

Pylkkänen, Liina. 2002. Introducing arguments. Doctoral dissertation, MIT, Cambridge, Mass.

Rappaport Hovav, Malka, and Beth Levin. 2001. An event structure account of English resultatives. Language 77:766-797.

Simpson, Jane. 1983. Resultatives. In Papers in Lexical-Functional Grammar, ed. by Malka Rappaport, Lori Levin, and Annie Zaenen, 143-157. Bloomington: Indiana University, Indiana University Linguistics Club.

Stechow, Arnim von. 1996. The different readings of wieder 'again': A structural account. Journal of Semantics 17.2:87-138.

Tenny, Carol. 1987. Grammaticalizing aspect and affectedness. Doctoral dissertation, MIT, Cambridge, Mass.

Travis, Lisa. 1994. Event Phrase and a theory of functional categories. In Proceedings of the 1994 Annual Conference of the Canadian Linguistics Association, ed. by Päivi Koskinen, 559-570. Toronto, Ont.: University of Toronto, Toronto Working Papers in Linguistics.

Wasow, Thomas. 1977. Transformations and the lexicon. In Formal syntax, ed. by Peter Culicover, Thomas Wasow, and Adrian Akmajian, 327-360. New York: Academic Press.

Wasow, Thomas. 1980. Major and minor rules in Lexical Grammar. In Lexical Grammar, ed. by Teun Hoekstra, Harry van der Hulst, and Michael Moortgat, 285-312. Dordrecht: Foris.

Wechsler, Stephen. 1997. Resultative predicates and control. In Proceedings of the 1997 Texas Linguistic Society Conference: The syntax and semantics of predication, ed. by Ralph C. Blight and Michelle J. Moosally, 307-321. Texas Linguistic Forum 38. Austin: University of Texas, Department of Linguistics.

Wechsler, Stephen. 2001. An analysis of English resultatives under the event-argument homomorphism model of telicity. In Proceedings of the Third Workshop on Text Structure, Oct. 13-15, 2000. Austin: University of Texas, Department of Linguistics.

Williams, Alexander. 2002. Complex causatives and verbal valence. Dissertation proposal, University of Pennsylvania, Philadelphia.

Winkler, Susanne. 1997. Focus and secondary predication. Berlin: Mouton de Gruyter.

Wunderlich, Dieter. 1997. Argument extension by lexical adjunction. Journal of Semantics 14.2:95-142.

Department of Linguistics

619 Williams Hall

University of Pennsylvania

Philadelphia, Pennsylvania 19104-6305

embick@ling.upenn.edu 